\title{
A STUDY OF THE MECHANISM OF INTERFACIAL POLYAMIDATION AND POLYESTERIFICATION
}

\author{
By \\ DONALD ÁLBERT HOLMER \\ Bachelor of Science \\ South Dakota School of Mines and Technology \\ Rapid City, South Dakota \\ 1956
}

Submitted to the Faculty of the Graduate School of the Oklahoma State University

in partial fulfillment of the requirements

for the degree of

DOCTOR OF PHILOSOPHY

May, 1961 
A STUDY OF THE MECHANISM OF INTERFACIAL

POLYAMIDATION AND POLYESTERIFICATION

Thesis Approved:

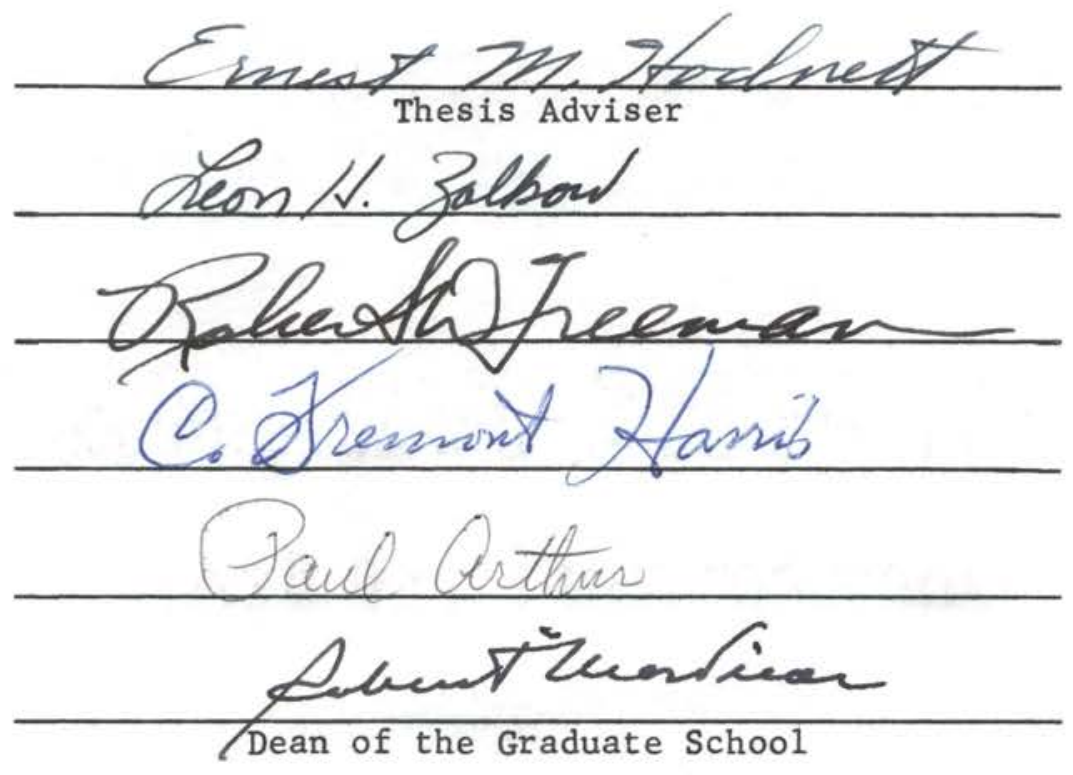


JAN 21962

\section{ACRNOWLEDGMENT}

Grateful acknowledgment is made to Dr. E. M. Hodnett, thesis adviser, for his assistance and guidance throughout this work.

Acknowledgment is also made for financial support by the Department of Chemistry and the Research Foundation in the form of a Research Fellowship supported by the Texaco Company and a Research Assistantship supported by the Atomic Energy Commission under Contract No. AT(11-1)71 , No. 5 .

This work was conducted in the facilities of the Radioisotopes and Radiations Laboratory. 
TABLE OF CONTENTS

Page

INTRODUCTION ........................... 1

HISTORICAL . . . . . . . . . . . . . . . . . . 2

Interfacial Polycondensation. . . . . . . . . . . . 2

Kinetics of Condensation Polymerization . . . . . . . . 4

The Kinetic Isotope Effect. . . . . . . . . . . . . 5

INTRODUCTION TO EXPERIMENTAL WORK. . . . . . . . . . . 9

Preliminary Investigation of Interfacial Reactions. . . . . 9

Monomers and Solvents............ 10

The Reactor. ................ 12

Stopping The Reactions .............. 12

Isolation and Purification of Polymers . . . . . . . 12

Molecular Weight Determination........... 13

Hydrolys is of Acid Chlorides . . . . . . . . . . 13

Migration of Monomers. . . . . . . . . . . . 14

Interfacial Polymerization Kinetics............. 14

Polyamidation. . . . . . . . . . . . . 15

Polyesterification . . . . . . . . . . . 15

Synthesis of Carboxy Carbon-14 Labeled Phthaloyl Chloride . . 15

Synthesis of Carboxy Carbon-14 Labeled Benzoyl Chloride . . . 17

Isotope Effect Study of Polyamidation . . . . . . . . . 17

Isotope Effect Study of Polyesterification. . . . . . . 19

Isotope Effects in Monoamidation. . . . . . . . . . . 19

EXPERIMENTAL DATA. .................. 21

Preliminary Investigation of Interfacial Reactions. . . . 21

Reactor.................. 21

Intrinsic Viscosity Measurements . . . . . . . . 21

Monomers and Solvents.............. 21

Hydrolys is of Phthaloyl Chloride .......... 23

Hydrolysis of Benzoyl Chloride........... 24

Monomer Diffusion Studies........... 24

Kinetics of Interfacial Polymerization. . . . . . . . . . 26

Polyamidation Kinetics . . . . . . . . . . 26

Polyesterification Kinetics. . . . . . . . . 27

Synthesis of Carboxy Carbon-14 Labeled Phthaloyl Chloride . . 28

Polymerizations Using Labeled Phthaloyl Chloride. . . . . . 29 
Synthesis of Carboxy Carbon-14 Labeled Benzoyl Chloride . . . 30 Monoamidation Using Labeled Benzoyl Chloride. . . . . . . . 30

RESULTS. . . . . . . . . . . . . . . . 34

Intrinsic Viscosities . . . . . . . . . . . . . . 34

Hydrolysis of Phthaloyl Chloride and Benzoyl Chloride... 34

Kinetics of Polyamidation .............. 34

Kinetics of Polyesterification............. 44

Monomer Diffusion Studies ............ 50

Polyamidation at Varying Monomer Ratios. . . . . . 50

Polyesterification at Varying Monomer Ratios . . . . 50

Piperazine and 4, 4'-Isopropylidene Diphenol Migration. . 50

Experimental Carbon-14 Isotope Effect in Polyamidation. . . . 56

Experimental Carbon-14 Isotope Effect in Polyesterification . 56

Experimental Carbon-14 Isotope Effect in Monoamidation. . . 56

DISCUSSION OF RESULTS. . . . . . . . . . . . . . 60

Intrinsic Viscosity . . . . . . . . . . . . . . 60

Hydrolysis of Phthaloyl Chloride and Benzoyl Chloride . . . 60

Kinetics of Polyamidation and Polyesterification. . . . . 60

Carbon-14 Isotope Effects . . . . . . . . . . 61

CONCLUSIONS. . . . . . . . . . . . . . . . . . 62

SUMMARY. . . . . . . . . . . . . . . . . 65

BIBLIOGRAPHY . . . . . . . . . . . . . . . 67 


\section{LIST OF TABLES}

Table

Page

I. Intrinsic Viscosities of Polyamides and Polyesters . . . . 35

II. Hydrolysis of Phthaloyl Chloride in Polyamidation. . . . 37

III. Hydrolysis of Phthaloy1 Chloride in Polyesterification . . 37

IV. Hydrolysis of Benzoyl Chloride in Monoamidation. .... 38

V. Polyamidation Kinetic Data ............. 39

VI. Polyamidation Rate Constants and Apparent Activation

Energy.................. 44

VII, Kinetics of Polyesterification ............ 45

VIII. Polyesterification Rate Constants and Apparent

Activation Energy. . . . . . . . . . . . 50

IX. Polyanidation at Varying Monomer Ratios.......... 51

X. Polyamidation Rate Constants at Varying Monomer Ratios . . 51

XI. Polyesterification at Varying Monomer Ratios . . . . . 53

XII. Polyesterification Rate Constants at Varying Monomer Ratios.................. 53

XIII. Monomer Migration into Carbon Tetrachloride. . ..... 55

XIV. Isotope Effect in Polyamidation. . . . . . . . 57

XV. Isotope Effect in Polyesterification .......... 58

XVI. Isotope Effect in Monoamidation............. 59 


\section{LIST OF FIGURES}

Figure

Page

1. Intrinsic Viscosity of Polymer L ........... 36

2. Polyamidation Kinetics -- I. . . . . . ..... 41

3. Polyamidation Kinetics - II .............. 42

4. Apparent Polyamidation Activation Energy ......... 43

5. Polyesterification Kinetics - I . . . . . . . 4 47

6. Polyesterification Kinetics - II. . . . . . . . . . 48

7. Apparent Polyesterification Activation Energy. . . . . . 49

8. Polyamidation at Varying Monomer Ratios......... 52

9. Polyesterification at Varying Monomer Ratios....... 54 


\section{INTRODUCTION}

The object of this work was to contribute to the knowledge of the recently discovered phenomenon of interfacial polycondensation. Interfacial polycondensations were studied by the use of chemical kinetics and the carbon-14 isotope effect in order to gain more insight into the reaction mechanism of polyamidation and polyesterification.

More specifically the problem has been: first, to study the kinetics of the reaction between phthaloyl chloride and piperazine; second, to study the kinetics of the reaction between phthaloyl chloride and 4, 4'. isopropylidene diphenol; third, to determine the carbon-14 isotope effect in the reaction of carboxy carbon-14 1abeled phthaloyl chloride with piperazine and with 4,4'-isopropylidene diphenol. Reactions were also studied using carboxy carbon-14 labeled benzoyl chloride and morpholine in order to determine any difference in isotopic effect between reactions involving monofunctional and bifunctional reactants. 


\section{HISTORICAL}

\section{Interfacial Polycondensation.}

Prior to the introduction of interfacial polycondensation, polyesters and polyamides were prepared principally by high-temperature reactions. Usually some step of the polycondensation required high vacuum thus necessitating the use of autoclaves. The total reaction time was ordinarily four to twenty-four hours (25). The drastic conditions involved in these high temperature reactions made mechanism studies difficult.

A patent issued to Magat and Strachan of the Textile Fibers Department of E. I. du Pont de Nemours and Company describes a method for preparing condensation polymers instantaneously at room temperature and atmospheric pressure (27). This method, involving polymerization at a liquid-1iquid interface, was further described in a series of papers presented in September, 1958, at the 134th meeting of the American Chemical Society by personnel of the du Pont Company (43). Techniques were revealed in these papers for preparing polyesters, polyurethanes, polyamides, and polysulfonamides by means of interfacial reactions. Essentially the methods involve the mixing of an aqueous solution containing a bifunctional alcohol or amine with a water-immiscible organic solvent containing a bifunctional acid chloride, chloroformate, or sulfonyl chloride. In all cases the aqueous solution must contain a base which will act as a proton acceptor thus tying up the hydrogen 
chloride produced and forcing the reaction toward completion.

The du Pont workers found that under certain conditions, particularly when the reactants both contained aliphatic chains, the polymeric amide film at the unstirred interface could be continuously pulled out of the interface to form a continuous cord. These polymeric films are formed in a fraction of a second; yet they are of a molecular weight sufficiently high for use in fibers and plastics.

Morgan and Kwolek (26) have speculated on the mechanism of the unstirred interfacial reactions, and their views may be summarized as follows:

1) Although there is little evidence, polyamidation and polyesterification are believed to proceed by nucleophilic attack on the acid chloride group by the amine or alcohol group.

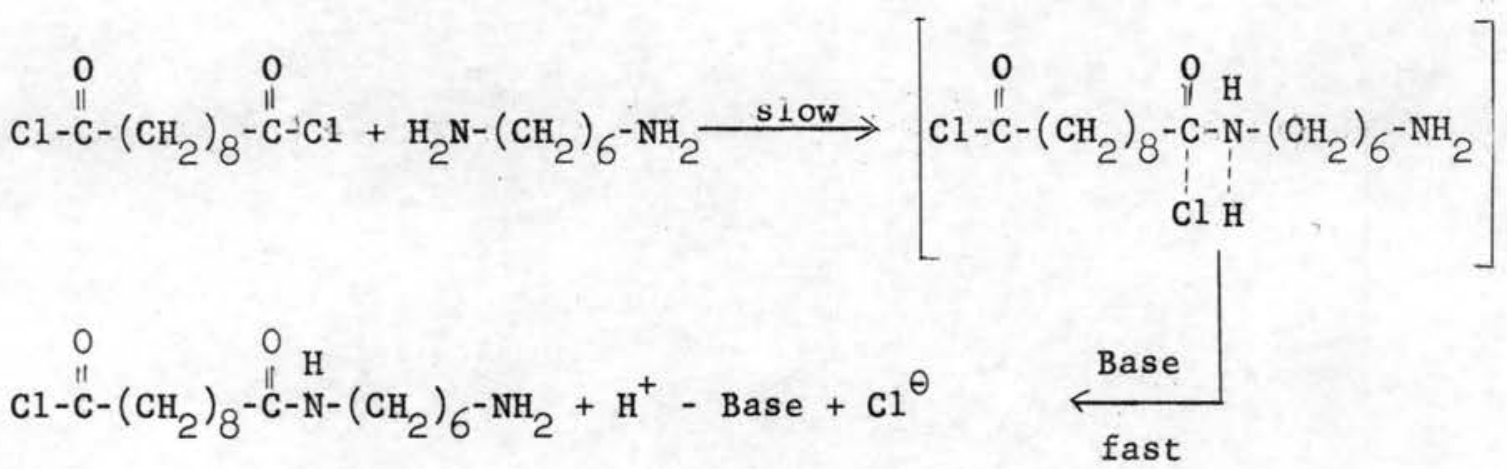

2) From electron micrographs of the interfacial films and from diamine partition coefficients, it is believed that polyamidation and polyesterification occur in the organic phase in the vicinity of the interface.

3) Experiments by a number of workers, notably Bunton (7) and Bohme (5), have shown that acid chloride hydrolysis, the main side reaction in interfacial condensations, occurs by an $\mathrm{S}_{\mathrm{N}} 1$ reaction in the 
aqueous phase exclusively. Therefore, the use of bifunctional acid chlorides which are highly insoluble in water is desirable in polymerization.

4) The polymers precipitate, with a fairly narrow molecular weight range, in the organic phase near the interface. If the nature of the polymers is such that they are swollen to a reasonable extent by the organic solvent, they may be pulled out of the interface to form continuous cords.

Kinetics of Condensation Polymerization.

As mentioned earlier, conventional polymerization in high temperature melts presents a rather difficult situation for kinetic studies. The major difficulties which are encountered include, first, the increase in the viscosity of the melt during the course of the reaction, and second, the continuous change in the nature of the medium due to removal from the melt of the molecules (water, ammonia, hydrogen chloride, alcohol, etc.) which are split out in the reaction.

Melt condensation presents a complete contrast to vinyl polymerization. In vinyl polymerization a polymer chain, once initiated, grows immediately to a high-molecular weight molecule. In melt condensation the weight of individual molecules very slowly increases as the reaction progresses; therefore, high-molecular weights cannot be obtained until the reaction has attained a high degree of completion. If one were to observe both vinyl and melt condensation in the very early stages of reaction, he would find in the case of vinyl polymerization a small amount of high molecular weight polymer and a large amount of unreacted monomer; in the case of melt condensation he would find most of the medium 
composed of dimers, trimers, tetramers, etc., together with unreacted monomer.

The majority of the work in polycondensation kinetics has been done by Flory and co-workers. The bulk of Flory's kinetic work has been with esterifications involving bifunctional alcohols and bifunctional acids. It was found that essentially no difference exists between polyesterification and esterification using monofunctional alcohols and acids. Uncatalyzed mono- and polyesterifications were found to be second order with respect to carboxyl groups and first order with respect to alcohol groups. Mono- and polyesterifications catalyzed by a strong acid (e.g., $\mathrm{p}$-toluenesulfonic acid) were found to be first order with respect. to carboxyl groups and first order with respect of hydroxyl groups $(12,13)$. The polycondensations were found to have activation energies in the vicinity of $25 \mathrm{kcal}$. per mole of repeating polymeric units. Similar studies by Flory on amidation (14) showed that polyamidation is a secondorder reaction. In all Flory's work on polycondensations reasonably straight line second order kinetic plots were obtained from about twenty to eighty per cent of complete reaction. At low extent of reaction the kinetic data were rather erratic and at high extent of reaction the rate appeared to decrease.

\section{The Kinetic Isotope Effect.}

It is known (33) that isotopic molecules do not react at identical rates particularly if a bond to an isotopic atom is broken or formed in the rate-determining step of a reaction. The isotope effect is the term used to describe this difference in reaction rates. Roginsky (32) has compiled an excellent theoretical treatment of the isotope effect. 
Carbon-14, the radioactive carbon isotope, has found wide usage in isotope effect work as well as tracer experiments. For the case of carbon-14 versus carbon-12 the magnitude of the effect is usually in the range of 4-10 per cent. Carbon-14 is prepared by neutron bombardment of nitrogen (22).

$$
7^{\mathrm{N}^{14}}+\mathrm{o}^{\mathrm{n}^{1}} \longrightarrow 6^{\mathrm{C}^{14}}+{ }_{1} \mathrm{H}^{1}+0.6 \mathrm{Mev}
$$

The isotope, which has a half-life of approximately 5,000 years, decays to nitrogen by emission of beta radiation of $0.145 \mathrm{Mev}$ (22).

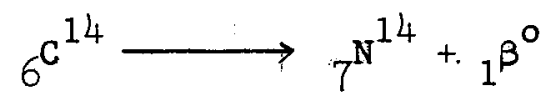

The beta radiation can be measured by ionization chamber, scintillation, or Geiger methods.

The magnitude of the experimental kinetic intermolecular isotope effect may be obtained from the following equation which has been derived by Stevens and Attree (38):

$$
\frac{k^{*}}{k}=\frac{\ln (1-r f)}{\ln (1-f)}
$$

$\begin{aligned} \text { where } \frac{k^{*}}{k}= & \text { the ratio of the reaction rate constant of the labeled } \\ & \text { molecule to that of the ordinary molecule in the reaction }\end{aligned}$

$$
\begin{aligned}
& \mathrm{A}+\mathrm{B} \stackrel{\mathrm{k}}{\longrightarrow} \mathrm{C} \\
& \mathrm{A}^{*}+\mathrm{B} \stackrel{\mathrm{k}^{*}}{\longrightarrow} \mathrm{C}^{*}
\end{aligned}
$$

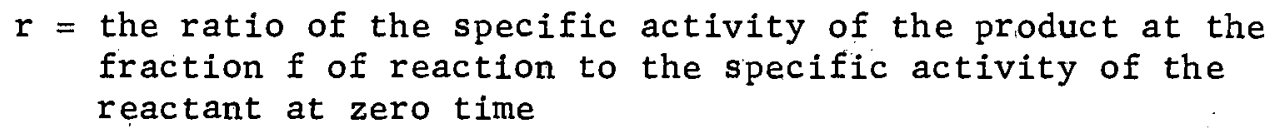

A similar expression involving only the reactant can be derived from the previous relationship:

$$
\frac{k^{*}}{k}-1=\frac{\log r^{*}}{\log (1-f)}
$$


where $r^{\prime}=$ the ratio of the specific activity of the reactant at the fraction $f$ of reaction to the specific activity of the reactant at zero time

The reaction should be stopped at low conversion when the product is used to follow the reaction. Conversely, when the reactant is used to follow the reaction, best results are obtained by analyzing the reactant present at high extent of reaction (4).

Recently considerable interest has been generated in certain areas in attempts to calculate theoretical isotope effects. Starting with the principles contained in the absolute reaction rate theory of Eyring, Bigeleisen (3) has developed the following general equation:

$$
k^{\prime}=\left(\frac{\mu^{\prime}}{\mu}\right)^{1 / 2}\left[1+\sum_{i}^{3 N-6} G\left(U_{i}\right) \Delta U_{i}-\sum_{j}^{3 N^{\prime}-6} G\left(U_{j}^{*}\right) \Delta U_{j}^{*}\right]
$$

for reactions in which the molecules involved have the same symmetry. The starred symbols refer to the activated complex, and the primed values refer to the labeled molecules. The reduced mass is symbolized by $\mu$, considering only those atoms which enter into the reaction. The terms in the brackets are sums of functions of the vibrational frequencies over 3N-6 degrees of vibrational freedom. Vibrational partition functions (2) appear in the $\mathrm{G}(\mathrm{U})$ term where

$$
\mathrm{U}=\frac{\mathrm{hc} \omega}{\mathrm{kT}}
$$

In this expression $\underline{h}$ is Planck's constant, $\underline{c}$ is the velocity of light, $\underline{\mathrm{k}}$ is Boltzmann's constant, $\underline{\mathrm{T}}$ is the absolute temperature, and $\underline{\omega}$ is the vibrational frequency of the bond being formed or broken. of course, to apply this equation quantitatively one must assume a shape for each potential energy surface and must further assume that the mass effect on the potential energy is negligible. The evaluation of vibrational 
partition functions is difficult for complex molecules; and for the evaluation of vibrational partition functions for the activated complex, one can only make a series of assumptions and educated guesses. Despite the inherent weaknesses involved in calculations using Bigeleisen's general equation and other more specific equations developed from it, numerous theoretical isotopic effects have been calculated which agree fairly well with experimental data. 


\section{INTRODUCTION TO EXPERIMENTAL WORK}

This investigation was to proceed according to the following plan. First, after the optimum conditions for interfacial polymerization were determined, separate kinetic studies of polyesterification and of polyamidation at several temperatures would be made in order to compare the rate constants and activation energies with similar data for melt condensations. Second, a carboxy carbon-14 labeled bifunctional acid chloride would be prepared. Third, a carboxy carbon-14 labeled monofunctional acid chloride would be synthesized. Fourth, an isotope effect study would be made to detect any differences in mechanism between simple amide formation and polyester and polyamide formation.

\section{Preliminary Investigation of Interfacial Reactions.}

The first step in the program was to select a satisfactory reactor, suitable monomers and solvents, most ideal concentrations, a method of stopping the reactions at low conversion, a means of isolating and purifying the polymers, and a method of checking the quality (molecular weight) of the polymers. It was also necessary to determine the amount of hydrolysis of the bifunctional acid chloride which would occur as a side reaction in the polymerization process. Furthermore, at this early stage of the program, it would be desirable to verify experimentally the physical mechanism of diffusion, polymerization, and precipitation which was suggested by the du Pont researchers. 
Monomers and Solvents: Phthaloyl chloride and hexamethylenediamine were the first monomers selected for polyamidation; however, hexamethylenediamine was later replaced by the secondary amine, piperazine, in order to rule out the possibility of imide formation as a side reaction.

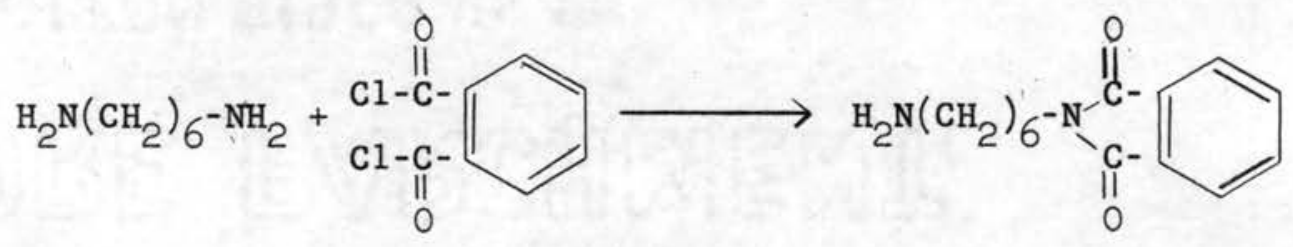

Imide Formation

The phthaloyl chloride-piperazine polycondensation may be represented as:

$\mathrm{n}$
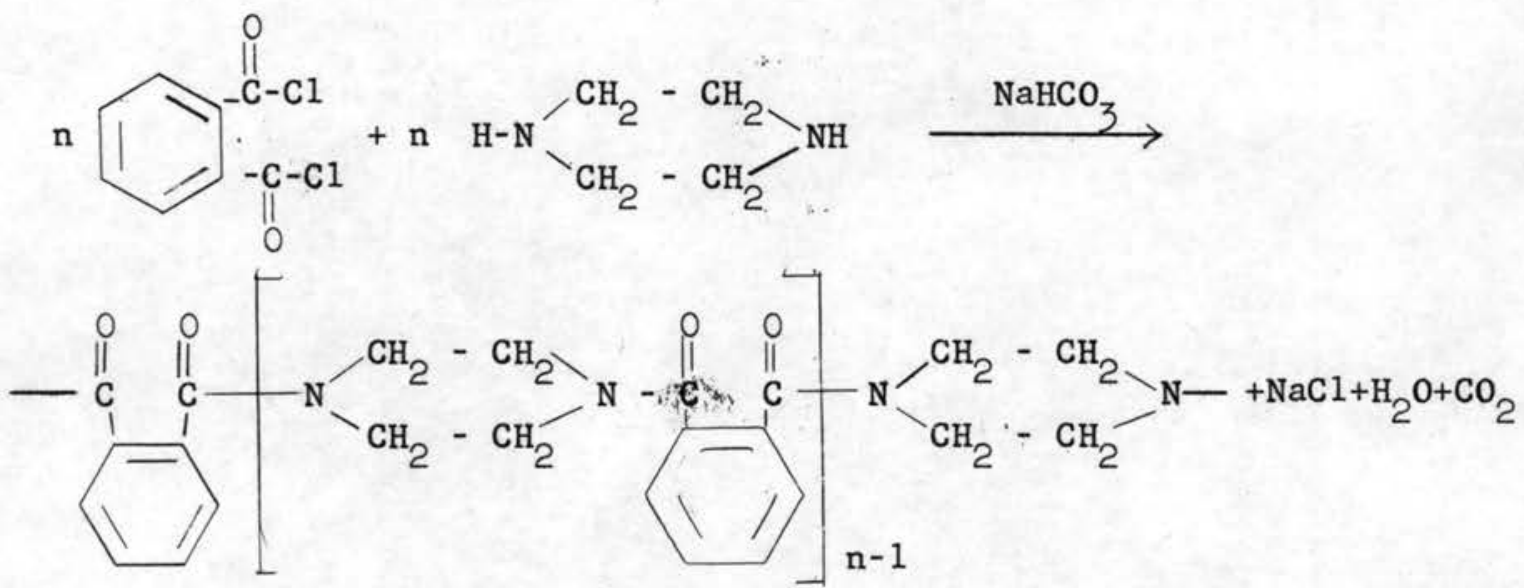

The sodium bicarbonate reacts with the hydrogen chloride formed, thus forcing the reaction toward completion.

Phthaloyl chloride was also chosen as the monomer in polyesterification. The aliphatic polyfunctional alcohols glycerine and ethylene glycol would not form interfacial polymers with phthaloyl chloride. The various polyphenolics invariably yielded tacky, colored polymers when reacted with phthaloyl chloride. Katz (18) suggested the use of 4, 4' isopropylidene diphenol as a monomer. Katz believes that the salt of the alcohol is the active species in the reaction. This fact would 
explain the failure to produce polymers from aliphatic polyfunctional alcohols. Experiments definitely showed the feasibility of the polyesterification reaction between phthaloyl chloride and 4,4'-isopropylidene diphenol... The reaction is represented in the following manner:

$\mathrm{n}$<smiles>O=C(Cl)c1ccccc1C(=O)Cl</smiles><smiles>[O-]c1ccccc1</smiles><smiles>CC(C)(C)c1ccc(Oc2ccc(C(C)(C)C)cc2)cc1</smiles><smiles>CCC(Oc1ccc(C(C)(C)c2ccc(Cl)cc2)cc1)(Oc1ccc(C(C)(C)c2ccc(OC(=O)c3ccccc3C(=O)c3ccccc3C(C)(C)C)cc2)cc1)C(=O)c1ccccc1</smiles>

$+\mathrm{H}_{2} \mathrm{O}+\mathrm{NaCl}+\mathrm{CO}_{2}$

Sodium carbonate is used as the hydrogen chloride acceptor in this condensation. Sodium bicarbonate will precipitate 4, 4'-isopropylidene diphenol from basic solutions.

Carbon tetrachloride was found to be the most desirable interfacial organic solvent for phthaloyl chloride. It was desired to investigate the specificity of the other phase in the interfacial reactions. Glutaronitrile was chosen as a possible substitute for water since it is immiscible with carbon tetrachloride and will dissolve small quantities of hexamethylenediamine, piperazine, and inorganic bases such as potassium hydroxide and sodium bicarbonate. Glutaronitrile was prepared according to the method of Marvel (24).

$$
\mathrm{Br}\left(\mathrm{CH}_{2}\right)_{3} \mathrm{Br}+\mathrm{NaCN} \longrightarrow \mathrm{NC}\left(\mathrm{CH}_{2}\right)_{3} \mathrm{CN}+\mathrm{NaBr}
$$

The glutaronitrile-carbon tetrachloride system failed to produce polyners. 
The specificity of water in the interfacial condensation is therefore indicated. Polyamidation and polyesterification proceeded at such a rate that the reactions could be easily controlled when monomer concentrations of approximately $0.06 \mathrm{molar}$ were used.

The Reactor: In order to achieve reproducible reaction rates, the media in which the reaction occurs must be stirred at high speed at a carefully controlled temperature. A Waring Blendor equipped with an internal coil and an external jacket through which fluid could be circulated from a constant-temperature bath was found to be very satisfactory. The double internal coil was constructed of $8 \mathrm{~mm}$. o. d. Pyrex tubing sealed permanently into the Bakelite blendor cap. The internal coil extended to within $1 / 8$ inch of the cutter blade assembly of the blendor. A thermometer was inserted through the cap to measure the temperature within the bulk of the emulsion. Fluid from the constant temperature bath was circulated first through the internal coil, then through the external rubber jacket, and then returned to the bath.

In all cases vessels containing solutions of the reactants were placed in the constant temperature bath, and fluid was circulated through the coll and Jacket of the empty blendor for at least thirty minutes prior to running the reactions,

Stopping The Reactions: It was found that the reactions could be stopped immediately by the addition of a slight excess of dilute hydroehloric acid to the emulsified mixture in the blendor.

Isolation and Purification of Polymers: After the reactions were stopped the emulsions were allowed to settle. The mixture was then filtered and the residue was washed thoroughly with dilute sodium bicarbonate solution and with water. The polyamides were then washed 
with acetone and the polyesters with aqueous Cellosolve solution. The polymers were then dried in a vacuum.

Molecular Weight Determination: Reasonably accurate absolute molecular weights of polymers are ordinarily obtained only after long, tedious measurements of osmotic pressure or light scattering. However, relative molecular weights based on viscometry (8) are widely used in polymer research as useful criteria for studying the number of variables in the formation of polymers. Accordingly, it was decided to use the intrinsic viscosity as a relative measure of molecular weight throughout the program. The intrinsic viscosity is defined as the specific viscosity at infinite dilution in a given polymeric solution.

The specific viscosity is given by the expression

$$
\eta_{\mathrm{sp}}=\left[\frac{\eta \mathrm{p}}{\eta \mathrm{s}}-1\right] \frac{1}{\mathrm{~m}}
$$

where $\eta_{\mathrm{p}}$ and $\eta_{\mathrm{s}}$ are the respective times of drainage of polymeric solution and pure solvent in the viscometer. A plot of $\eta_{s p}$ versus $c$ is then extrapolated to infinite dilution to obtain the intrinsic viscosity.

$$
\operatorname{Lim}_{c \rightarrow 0} \eta_{s p}=[\eta]
$$

In these expressions $\subseteq$ is the polymer concentration in grams per 100 milliliters of solution, $\underline{m}$ is the concentration in moles per liter of solution, and [ $\eta]$ is the intrinsic viscosity. For each intrinsic viscosity determination five to seven polymer concentrations in the range $0<c \leqslant 1$ were used. The determinations were made in Cannon-Fenske Viscometers in a constant temperature bath controlled to $\pm 0.02^{\circ}$. Hydrolysis of Acid Chlorides: It was desired to know the extent 
of hydrolysis of both phthaloyl chloride and the monofunctional acid chloride to be used later in the program. This problem was accomplished by reacting carbon tetrachloride solutions of the acid chlorides with water in the blendor. In the case of phthaloyl chloride the water contained sodium carbonate in one series and sodium bicarbonate in the other series. For each system the phases were mixed in the blendor. At various times samples were withdrawn from the water layer of the reaction medium and acidified with nitric acid. Silver nitrate was then used to precipitate any chloride ions in the solution. From the weights of silver chloride obtained, one could obtain the extent of hydrolysis occurring as a side reaction during the condensations.

Migration of Monomers: The du Pont researchers (26) have speculated that monomers from the aqueous phase migrate into the organic phase. Polymerization would then occur in the organic phase in the vicinity of the interface. The direction of monomer migration was studied first by varying the ratio of one monomer to the other monomer and determining the intrinsic viscosities of the resulting polymers. Next a study was made of the migration of piperazine and of 4, 4'-isopropylidene diphenol from water into carbon tetrachloride in blendor emulsions. From these data one should be able to determine the direction of monomer migration and the site of polymerization.

\section{Interfacial Polymerization Kinetics.}

Several points should be emphasized before the work performed in the laboratory on interfacial polymerization kinetics is described. One is dealing with a highly complex system involving a liquid-liquid interface. The rate constants obtained will depend on the rate of mixing. 
The activation energies obtained are not true activation energies, because an increase of temperature not only increases the energy of the molecules and the number of collisions per second but also changes the viscosity of the individual phases and the interfacial tension: The experimental activation energies will be referred to as apparent activation energies.

Polyamidation: Reactions were studied in a blendor at $0^{\circ}, 30^{\circ}$, and $50^{\circ}$. The reactions in replicate experiments were stopped at various times and the products were isolated, purified, and weighed. The reaction rate constants were calculated at the three temperatures, and the apparent activation energy was determined from these rate constants. Polyesterification: The procedure used in this phase of the work was similar to the procedure used in the polyamidation kinetics.

Synthesis of Carboxy Carbon-14 Labeled Phthaloy1 Chloride.

It was decided to employ the method of Murray and Williams (28) for the synthesis of carboxy carbon-14 labeled phthaloyl chloride. These workers reported the synthesis of carboxy carbon-14 1abeled dimethy 1 phthalate by the following scheme:

$$
\mathrm{BaCO}_{3}+\mathrm{H}_{2} \mathrm{SO}_{4} \longrightarrow \stackrel{*}{\mathrm{C}} \mathrm{O}_{2}+\mathrm{H}_{2} \mathrm{O}+\mathrm{BaSO}_{4}
$$

1) $\mathrm{Mg}$<smiles>Cc1ccccc1Br</smiles>

2) $\mathrm{CO}_{2}$

3) $\mathrm{H}^{\oplus}$<smiles>CCOc1ccccc1C</smiles><smiles>Cc1ccccc1C(=O)O</smiles>

1) $\mathrm{MnO}_{4}^{\ominus} \cdot \mathrm{OH}^{\ominus}$<smiles>O=C(O)c1ccccc1C(=O)O</smiles> 


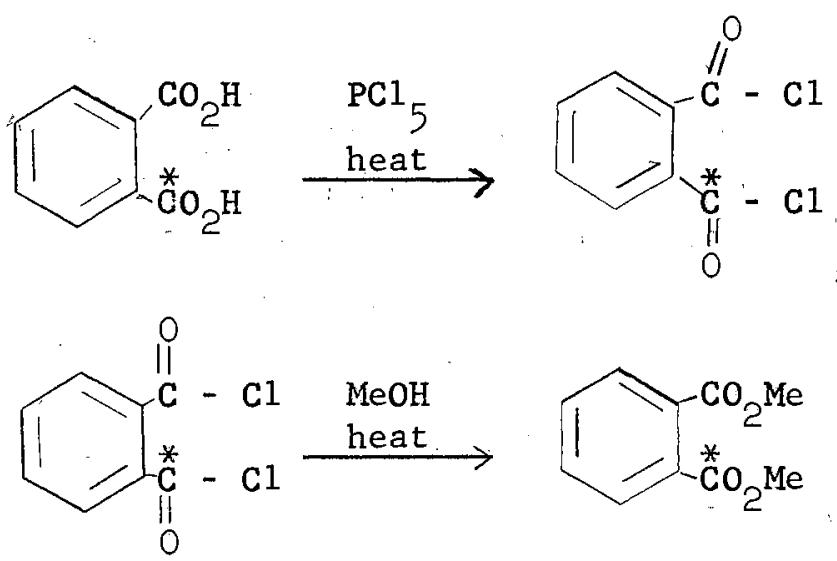

A series of preliminary experiments showed the feasibility of the first three steps in the above synthesis; however, the chlorination step is highly unsatisfactory, giving a considerable amount of phthalic anhydride. Several alternate methods were investigated for chlorinating phthalic acid.

When phthalic acid was treated with thionyl chloride, the main product obtained was the anhydride. The methods of Reissert and Holle (31) and 0tt, Langenoh1, and Zeirweck were next investigated (29). These workers reported a phthaloyl chloride synthesis in which phthalic anhydride is supposedly converted to thiophthalic anhydride upon treatment with sodium sulfide. The thiophthalic anhydride is then melted and chlorinated with chlorine gas. All attempts at this synthesis failed. Kyrides (10) reported a phthaloyl chloride synthesis in which phthalic anhydride was treated with thionyl chloride in the presence of anhydrous zinc chloride. With the use of phthalic anhydride this synthesis worked beautifully; however, attempts to substitute phthalic acid for phthalic anhydride in the synthesis failed to produce any phthaloyl chloride.

The industrial preparation of phthaloyl chloride which involves a complex reaction between phthalic anhydride, phosgene, and $\mathrm{N}, \mathrm{N}$-dimethyl- 
formamide would be rather difficult to apply to a small scale synthesis. After the above methods for converting phthalic acid to phthaloyl chloride were analyzed, it was decided to try a simpler procedure, namely, an exchange between carbon-14 1abeled phthalic acid and unlabeled phthaloyl chloride. If this exchange failed one still could recover the phthalic acid, convert it to phthalic anhydride with thiony1 chloride, and chlorinate it with thionyl chloride in the presence of zinc chloride.

Synthes is of Carboxy Carbon-14 Labeled Benzoyl Chloride.

Carboxy carbon-14 labeled benzoyl chloride was prepared according to the following scheme:

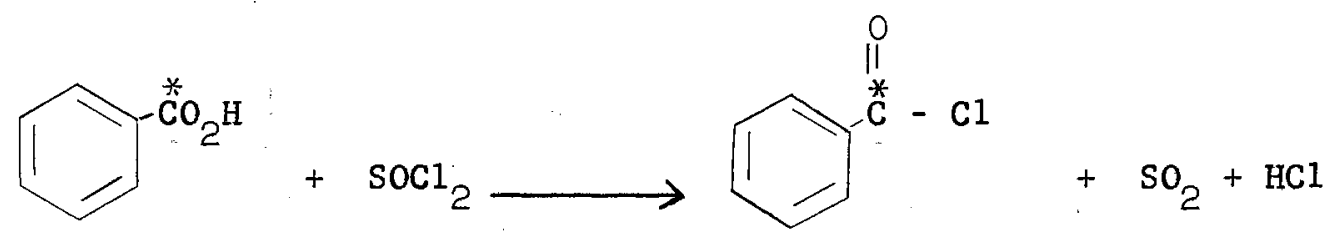

Isotope Effect Study of Polyamidation.

Four reactions were run using carboxy carbon-14 labeled phthaloy1 chloride, piperazine, and sodium bicarbonate in the water-carbon tetrachloride system. Two polymerizations were run to essentially 100 per cent reaction, and two polymerizations were stopped at low conversion. Because the radioactivity assays of liquid samples could not be performed with good precision using the wet combustion method, the activity of the reactant in the form of phthaloyl chloride was not determined. However, the molar activity of the polymer per repeating unit at 100 per cent conversion should equal that of the monomer. The Stevens and Attree equation may be applied, as the specific activity of the high conversion (100 per cent) polymer would be equal to the specific activity of the 
reactant.

In practice conversions of 100 per cent are difficult to achieve; therefore, the Stevens and Attree equation may be rearranged (17) so that the isotope effect can be calculated from the specific activities of two polymer samples of different degrees of conversion from a given sample of phthaloyl chloride.

$$
\frac{k^{*}}{k}=\frac{\ln (1-r f)}{\ln (1-f)}
$$

Let $\mathrm{k}=\frac{\ln \left[1-\frac{\left.\mathrm{n}_{1} \mathrm{f}_{1}\right]}{\mathrm{k}}\right]}{\ln \left(1-\mathrm{f}_{1}\right)}=\frac{\ln \left[1-\frac{\mathrm{n}_{2} \mathrm{f}_{2}}{\mathrm{x}}\right]}{\ln \left(1-\mathrm{f}_{2}\right)}$

where $\mathrm{K}=\frac{\mathrm{k}^{*}}{\mathrm{k}}$

$x=$ the specific activity of phthaloyl chloride

$n_{1}=$ the specific activity of polymer at fraction of reaction $f_{1}$

$n_{2}=$ the specific activity of polymer at fraction of reaction $f_{2}$

$\ln \left[\frac{1-n_{1} f_{1}}{x}\right]=K \ln \left(1-f_{1}\right)$

$-\left[{\frac{n_{1}}{x}}^{f_{1}}\right]=\left(1-f_{1}\right)^{k}-1$

$x=\frac{-n_{1} f_{1}}{\left(1-f_{1}\right)^{R}-1}$

also $\left[\frac{-n_{2} f_{2}}{x}\right]=\left(1-f_{1}\right)^{K}-1$

eliminating $x$

$$
\begin{aligned}
& \frac{n_{2} f_{2}}{n_{1} f_{1}}\left[\left(1-f_{1}\right)^{K}-1\right. \\
& n_{2} f_{2}\left(1-f_{1}\right)^{K}-n_{1} f_{1}\left(1-f_{2}\right)^{K}=n_{2} f_{2}-n_{1} f_{1}
\end{aligned}
$$


and

$$
\left(1-f_{1}\right)^{K}-\frac{n_{1} f_{1}}{n_{2} f_{2}}\left(1-f_{2}\right)^{K}+\frac{n_{1} f_{1}}{n_{2} f_{2}}-1=0
$$

In using this equation, which can be solved for $\mathrm{K}$ by a method of successive approximations, the specific activity of the initial reactant need not be known.

The samples were prepared for radioactivity assay by the wet combustion method, and the assays were determined with a vibrating reed electrometer.

Isotope Effect Study of Polyesterification.

Four reactions were run using carboxy carbon-14 labeled phthaloyl chloride, sodium 4, 4'-isopropylidene diphenolate, and sodium carbonate in the water-carbon tetrachloride system. Two polymerizations were run to low conversion and two polymerizations were run to high conversion. The polymers were assayed and the experimental isotope effects calculated as described in the previous section.

Isotope Effects in Monamidation.

For the monoamidation reaction between labeled benzoyl chloride and morpholine a slightly different procedure was used. A sample of the benzoyl chloride was hydrolyzed completely to benzoic acid. The benzoic acid was assayed in order to determine the specific activity of the benzoyl chloride. Two amidation reactions were then run to low extent completion, and the products were assayed for radioactivity. 


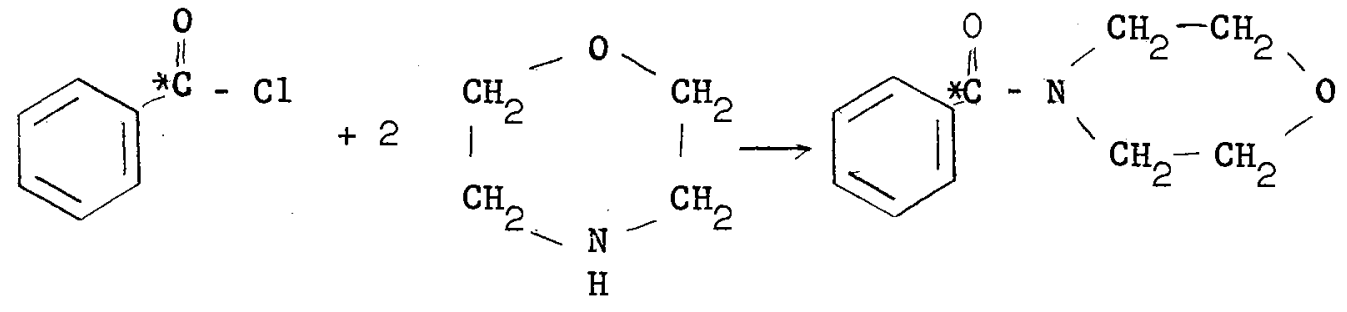

$$
+\left.\right|_{\mathrm{H}_{\mathrm{H}}^{\oplus} \mathrm{Cl}^{\ominus}} ^{\mathrm{CH}_{2}^{-}}{ }_{\mathrm{CH}_{2}}^{\mathrm{CH}_{2}}
$$




\section{EXPERIMENTAL DATA}

\section{Preliminary Investigation of Interfacial Reactions.}

Reactor: The modified blendor apparatus described earlier was constructed, and this reactor was used throughout the course of the program. In all cases the General Radio Company Variac variable transformer setting was maintained at 80 volts. No allowance was made for variations in the line voltage. The various constant temperature baths, from which coolant fluids were pumped through the reactors, were maintained at $0.0 \pm 0.1^{\circ}, 30.00 \pm 0.02^{\circ}$, and $50.00 \pm 0.02^{\circ}$.

Intrinsic Viscosity Measurements: The specific viscosities were run in a series of Cannon-Fenske viscometers immersed in a $26.62 \pm 0.02^{\circ}$ constant temperature bath. In these determinations extreme care must be taken in cleaning and drying the viscometers prior to use, as any trace of residue in the viscometers will give highly erroneous readings. Furthermore, the solutions used must be free of suspended particles and the solutions in the viscometers must remain in the bath for at least 30 minutes and preferably an hour before measurements are made. One hundred per cent sulfuric acid was used as a solvent for the phthaloyl chloridehexamethylenediamine polymers and $\underline{m}$-cresol was used as a solvent for the phthaloyl chloride--piperazine and phthaloyl chloride--4, 4'-isopropylidene diphenol polỳmers. Ten milliliters of solution were used in each determination.

Monomers and Solvents: A number of factors were involved in choosing 
appropriate monomers and solvents. It was desired to obtain polymers which could be readily isolated. For this reason organic solvents were discarded if they tended to dissolve or swell the polymers. Similarly it was necessary to discard solvents which formed emulsions that separated slowly and made filtration extremely difficult. Another factor of lesser importance was flammability, which must be taken into consideration when reactions are run for extended periods in Waring Blendors with open motors. After all of these factors were considered, carbon tetrachloride was chosen after an experimental evaluation of solvents which included benzene, toluene, $\mathrm{p}$-xylene, and chloroform. As mentioned previously all attempts to use glutaronitrile as a substitute for water failed.

The reasons for choosing piperazine and discarding hexamethylenediamine were given earlier. The choice of 4,4'-isopropylidene diphenol was the result of a number of polymerization experiments using various bifunctional alcohols. Ethylene glycol and glycerine would not polymerize with phthaloyl chloride. Catechol and resorcinol gave small yields of swollen, colored polymers. The colors became more intense as the base was varied from sodium bicarbonate to sodium carbonate to sodium hydroxide. Hydroquinone gave good yields of colored, powdery polymers when sodium hydroxide was used as the acid acceptor and colored swollen polymers when sodium bicarbonate or sodium carbonate were employed as bases. The color in these polymers is probably due to varying degrees of basic phenolic oxidation.

Phthaloyl chloride was chosen as a monomer for two reasons. First, it was thought that steric factors involving this monomer would slow the polymerization reactions. Second, it was thought that carboxy carbon-14 
labeled phthaloyl chloride could be easily synthesized.

Hydrolysis of Phthaloyl Chloride: It was desired to know the extent of hydrolysis of phthaloyl chloride in the course of the polymerization reactions. Accordingly, the following interfacial hydrolysis systems were used to determine the amount of phthaloyl chloride hydrolysis in the presence of aqueous sodium carbonate and sodium bicarbonate.

Sodium bicarbonate system:

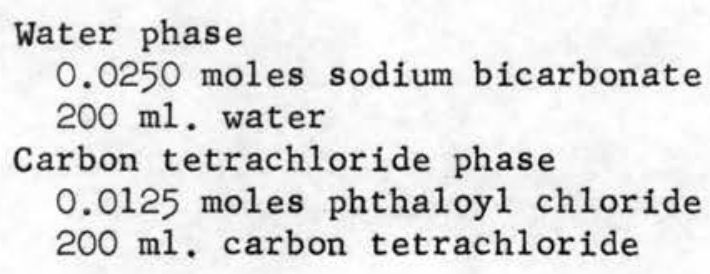

Sodium carbonate system:

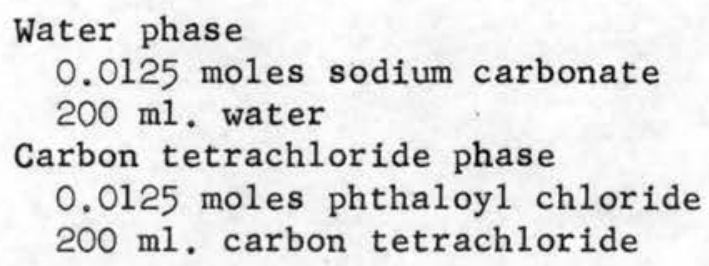

For each system the phases were mixed in the blendor at $0^{\circ}$ and allowed to react for a given time. Fifty-milliliter samples were withdrawn from the water layer of the reaction medium and acidified with nitric acid. An excess of silver nitrate was added to the acidic solution, and the mixture was heated gently to boiling. The mixture was allowed to cool and was then filtered through a weighed, fritted-glass filter. The precipitate was washed with water and with $\mathrm{N}, \mathrm{N}$-dimethylformamide, dried, and weighed. The N,N-dimethylformamide dissolves any phthalic acid in the precipitate. A series of such runs was made. From the weights of silver chloride obtained after various times in the blendor, one could obtain the extent of hydrolysis of phthaloyl chloride occurring as a side reaction during the polymerization runs. 
Hydrolysis of Benzoyl Chloride: It was necessary to know the extent of benzoyl chloride hydrolysis occurring as a side reaction in the amidation of benzoyl chloride with monofunctional amines. The following system was therefore used to study interfacial benzoyl chloride hydrolysis:

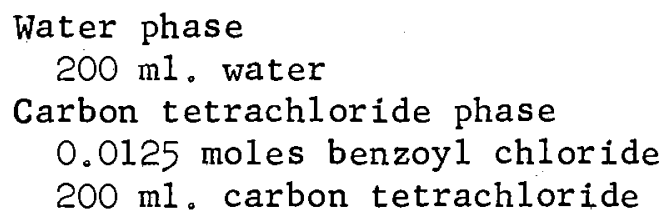

The phases were mixed in the blendor at $0^{\circ}$. Fifty-milliliter samples were withdrawn from the water layer of the reaction medium and acidified with nitric acid. Silver nitrate was added to the acidic solution and the mixture was heated gently to boiling. The mixture was cooled and filtered through a weighed, fritted-glass filter. The precipitate was washed with water and with diethyl ether, dried, and weighed. Diethyl ether dissolves any benzoic acid in the precipitate. The weights of silver chloride obtained from a series of such runs gives a measure of the extent of benzoyl chloride hydrolysis.

Monomer Diffusion Studies: It was thought that the mechanism of diffusion could best be studied by observing the yields and intrinsic viscosities obtained at varying. monomer ratios, and correlating this information with a study of the migration of piperazine and 4, 4'-isopropylidene diphenol from water into carbon tetrachloride in blendor emulsions. Experiments were performed using the following proportions:

Polyesterification Case I

Water phase

0.0625 moles $4,4^{8}$-isopropylidene diphenol

0.1250 moles sodium hydroxide

0.0125 moles sodium carbonate

$200 \mathrm{ml}$. water 
Carbon tetrachloride phase

0.0125 moles phthaloyl chloride

$200 \mathrm{~m} 1$. carbon tetrachloride

Polyesterification Case II

Water phase

0.0125 moles $4,4^{\prime}$-isopropylidene diphenol

0.0250 moles sodium hydroxide

0.0125 moles sodium carbonate

$200 \mathrm{~m} 1$. water

Carbon tetrachloride phase

0.0625 moles phthaloyl chloride

$200 \mathrm{ml}$. carbon tetrachloride

Polyamidation Case I

Water phase

0.0625 moles piperazine

0.0250 moles sodium bicarbonate

$200 \mathrm{ml}$. water

Carbon tetrachloride phase

0.0125 moles phthaloyl chloride

$200 \mathrm{ml}$. carbon tetrachloride

Polyamidation Case II

Water phase

0.0125 moles piperazine

0.0250 moles sodium bicarbonate

$200 \mathrm{ml}$. water

Carbon tetrachloride phase

0.0625 moles phthaloyl chloride

$200 \mathrm{ml}$. carbon tetrachloride

The polymerizations were run for various times at $0^{\circ}$ in the blendor. The

polymers were isolated, purified, weighed, and the intrinsic viscosities

determined.

The migration of piperazine and $4,4^{\circ}$-isopropylidene diphenol was

studied in the following experiments:

Piperazine migration

Water phase

0.0125 moles piperazine

0.0250 moles sodium bicarbonate

$200 \mathrm{ml}$. water

Carbon tetrachloride phase

$200 \mathrm{~m} 1$. carbon tetrachloride 


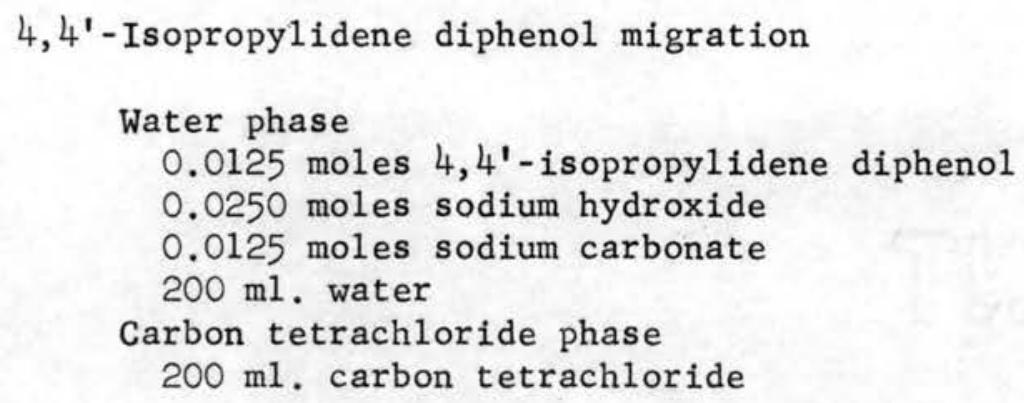

The phases were blended at $0^{\circ}$, and at various times the blendors were stopped. Fifty-milliliter samples were withdrawn from the carbon tetrachloride layers. These samples were placed under slightly reduced pressure to remove the solvent. From the weight of residue obtained at various times, one can determine the extent of monomer diffusion from water into carbon tetrachloride. The 4, 4'-isopropylidene diphenol residues were identified by their melting points.

\section{Kinetics of Interfacial Polymerization.}

Polyamidation Kinetics: The kinetics of the following system were studied at $0^{\circ}, 30^{\circ}$, and $50^{\circ}$ :

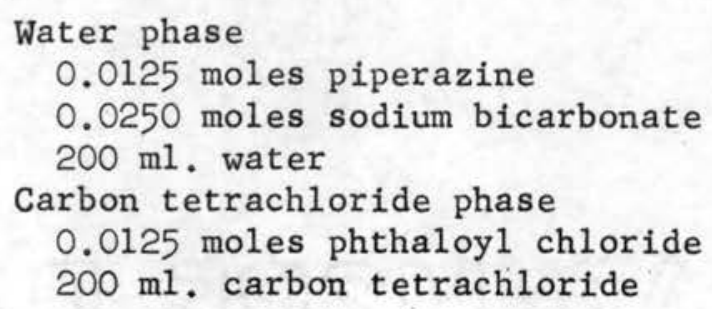

Anhydrous piperazine (Eastman Practical Grade) was recrystallized twice from benzene and stored in a desiccator containing sodium hydroxide pellets and Linde Molecular Sieve No. 4A. Phthaloyl chloride (Eastman Practical Grade) was dried over Linde Molecular Sieve No. 5A and then fractionated in a heated Vigreaux column at $12 \mathrm{~mm}$. (b. p. $140^{\circ}$ ). The carbon tetrachloride was distilled and then passed through a column packed with Linde Molecular Sieve No. 5A. 
The above phases were emulsified at a blendor speed resulting from a variable transformer setting of 80 volts. The reactions in replicate experiments were stopped at various times by the addition of dilute hydrochloric acid solution. The emulsions were filtered and the polymers were washed successively with one per cent sodium bicarbonate solution, with water, and with acetone. The polymers were white, powdery solids. The rate constants were calculated for the three temperatures, and the apparent activation energy was determined from these constants.

Polyesterification Kinetics: A kinetic study of polyesterification was carried out at $0^{\circ}, 30^{\circ}$, and $50^{\circ}$ using the following system:

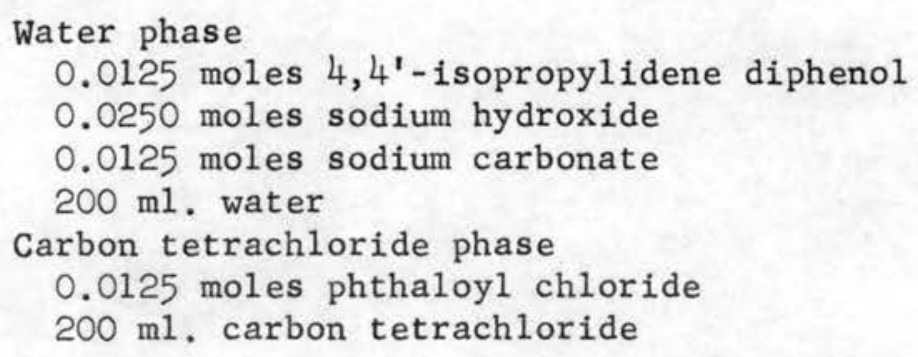

The 4, 4'-isopropylidene diphenol (Eastman Reagent Grade) was recrystallized from benzene solution. The purified product melted at $157.5-158.0^{\circ}$. The water phase solution was prepared by adding the sodium hydroxide and 4, 4'-isopropylidene diphenol to fifty milliliters of water. Agitation of fifteen to thirty minutes on an automatic shaker was usually required in order to dissolve the diphenol. The resulting solution was then diluted with sodium carbonate solution to produce the final reactant solution.

The phases were emulsified for varying times. The reactions were stopped by the addition of dilute hydrochloric acid. The acid not only stopped the polymerization but also precipitated the unreacted $4,4^{\circ}$-isopropylidene diphenol. It was found that a solution containing 9 per cent 
water and 91 per cent Cellosolve (2-ethoxy-1-ethanol) would quantitatively extract 4,4'-isopropylidene diphenol from a mixture of polyester and 4,4'-isopropylidene diphenol. Removal of the solvent from the Cellosolvewater solutions gave essentially 100 per cent yields of 4,4'-isopropylidene diphenol with a melting point of $157.5^{\circ}$. After Cellosolve extraction the polymers were washed with water, dried, and weighed. Again, from the rate constants for the three temperatures, the apparent activation energy was determined.

Synthesis of Carboxy Carbon-14 Labeled Phthaloyl Chloride.

The procedure for the complete synthesis of carboxy carbon-14 labeled phthaloyl chloride from carbon-14 barium carbonate was as follows. Carbon dioxide was liberated from $2.4356 \mathrm{~g}$. (5 millicuries) of barium carbonate with excess concentrated sulfuric acid. The carbon dioxide was transferred on a vacuum line to a tube containing an ether solution of a Grignard reagent ( 10 per cent molar excess) prepared from o-bromotoluene (Eastman Reagent Grade) and magnesium. The tube was then sealed, removed from the liquid nitrogen cold trap, and allowed to warm slowly to room temperature while being slightly agitated from time to time to promote mixing. After several hours the tube was opened, and the contents were acidified with dilute hydrochloric acid. This mixture was extracted with ether, and the ether evaporated. The ether residue was treated with concentrated sodium hydroxide solution and extracted with ether. The sodium hydroxide solution was then acidified to $\mathrm{pH} 1$ with hydrochloric acid and extracted with ether. The ether was evaporated, leaving solid o-toluic acid as a residue. The o-toluic acid was then oxidized on a steam bath with a 10 per cent excess of basic potassium 
permanganate solution for ten hours. The excess oxidant was destroyed with ethyl alcohol, the mixture acidified to $\mathrm{pH} 2$, and sodium bisulphite was added to dissolve the precipitated manganese dioxide. The solution was concentrated on a steam bath, cooled, and the crystals of phthalic acid collected on a filter. The phthalic acid was then placed in a sealed tube with 30 milliliters of freshly vacuum-fractionated phthaloyl chloride. The mixture was agitated with a magnetic stirrer for 94 hours at room temperature. The mixture was vacuum fractionated and the distillate collected in four tubes which were then vacuum sealed.' Chloride analysis and refractive index showed the distillate to be essentially pure phthaloyl chloride. A Beckmann freezing point determination indicated the absence of detectable impurities in the phthaloyl chloride. Phthaloy1 Chloride

$\begin{array}{lll}\mathrm{n}_{D} 20 & \frac{\text { found }}{1.5692} & \frac{1 \text { iterature (21) }}{1.5692} \\ \mathrm{~m} . \mathrm{p} . & 16.1 & 16 \\ \% \mathrm{Cl} 1 & 34.91 & 34.93\end{array}$

Polymerizations Using Labeled Phthaloyl Chloride.

Two 0.0125-mole samples of "labeled" phthaloyl chloride were removed from each of the four vials of distillate described in the previous section. One sample from each of two vials was run to high conversion (18 hours) of polyamide; the remaining samples in each of these two vials were run to low polyamide conversion. One sample from each of the two remaining vials was run to high polyester conversion (18 hours), and one sample from each of these two vials was run to low polyester conversion. Polymer samples of 5-10 mg. each were weighed into platinum boats 
on a microbalance. The samples were then transferred to a wet-combustion apparatus and oxidized to carbon dioxide with hot Van Slyke solution (30). The radioactive carbon dioxide was flushed out with ordinary carbon dioxide and expanded into an evacuated stainless steel ionization chamber. The ionization chamber was connected to an Applied Physics Corporation, Model 30 Vibrating Reed Electrometer. The millivolt readings from the vibrating reed electrometer were converted to microcuries/ millimole ( $\mu \mathrm{c} . / \mathrm{mmole}$ ) with the aid of the following constants:

$1.39 \times 10^{-16}$ coulombs/disintegration (for carbon-14 in carbon dioxide)

$3.7 \times 10^{10}$ disintegrations/second for one curie

$0.96 \times 10^{10}$ ohms (resistance of electrometer)

Synthesis of Carboxy Carbon-14 Labeled Benzoyl Chloride.

Carboxy carbon-14 1abeled benzoyl chloride was readily prepared by chlorinating carbon-14 labeled benzoic acid. The labeled benzoic acid had previously been prepared in the laboratory by R. L. Rowton (34). A 100 per cent excess of thionyl chloride was refluxed with $6.9498 \mathrm{~g}$. of labeled benzoic acid for two hours. The excess thionyl chloride was removed by distillation under reduced pressure. The benzoyl chloride was then distilled through a heated Vigreaux column at $10 \mathrm{~mm}$. pressure (b. p. $\left.73^{\circ}\right)$.

Benzoyl Chloride

$\mathrm{n}_{\mathrm{D}}^{20} \quad \frac{\text { found }}{1.5536} \quad \frac{\text { 1iterature (21) }}{1.5537}$

Monoamidation Using Labeled Benzoyl Chloride.

The last phase of the experimental program was to be an isotope effect study of a simple interfacial monoamidation. The following 
experiment was attempted using piperidine, benzoyl chloride, and pyridine:

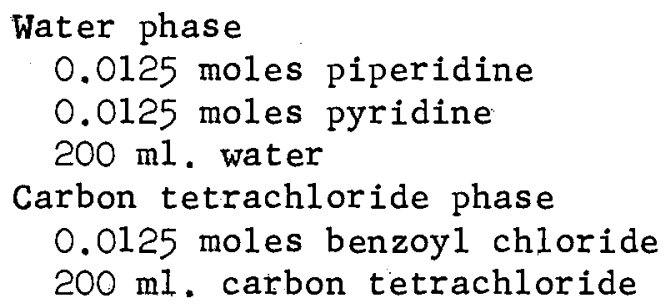

The phases were blended at $0^{\circ}$ for 30 minutes. The reactions were stopped by addition of dilute hydrochloric acid. The carbon tetrachloride phase was separated and the solvent distilled under reduced pressure. The residue remained as an oil and all attempts to crystallize it failed. The literature (16) lists the melting point of the amide at $48^{\circ}$; such a low melting point would probably account for the difficulty encountered in the attempted crystallization.<smiles>O=C(Cl)c1ccccc1</smiles>

It was decided at this point to substitute morpholine for piperidine:

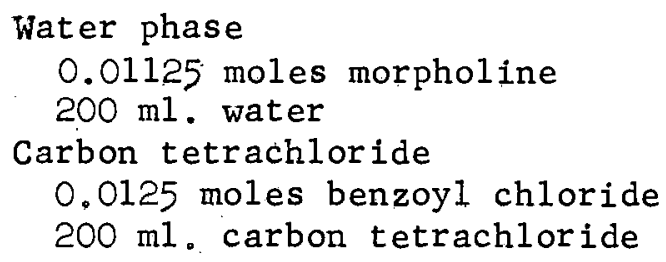

In this experiment morpholine served as both amidation reactant and proton acceptor. 


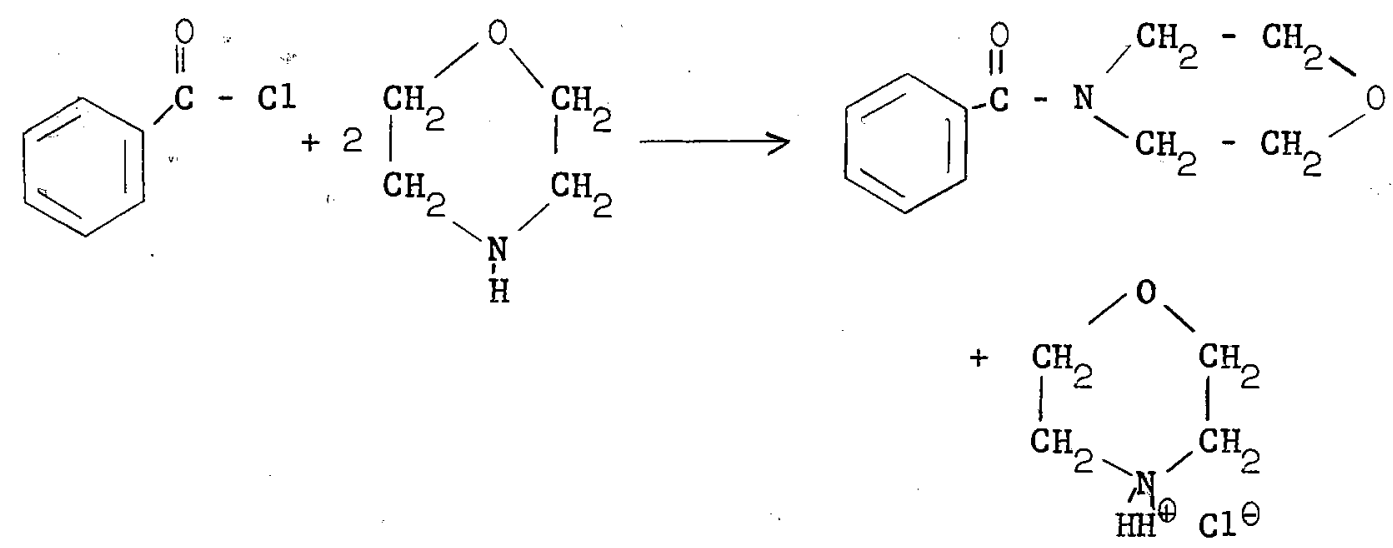

The ratio of benzoyl chloride to morpholine was chosen so as to dxive the reaction to high conversion in a reasonable length of time.

$$
\frac{\text { moles morpholine }}{\text { moles benzoyl chloride }}=\frac{0.01125}{0.0125}=0.9
$$

The reaction was stopped after 90 minutes by addition of dilute hydrochloric acid. The carbon tetrachloride layer was separated and the solvent distilled under reduced pressure. The residue was covered with saturated sodium bicarbonate solution for 24 hours. The amide was recovered by extraction with benzene, followed by evaporation of the benzene. The amide was weighed and then recrystallized twice from hot water. The yield was 94 per cent based on 0.01125 moles of morpholine, or stated in a different manner, the yield was 84 per cent based on 0.0125 moles of benzoyl chloride. The melting point was $74.5-75.0^{\circ}$; 1it. (16) $75^{\circ}$.

The benzoyl chloride used in these experiments was Mallinckrodt Reagent Grade. The reagent was dried over Linde Molecular Sieve No. 4A, fractionated at $10 \mathrm{~mm}$. in a heated Vigreaux column, and sealed into tubes under a vacuum. The morpholine (Fisher Reagent Grade) was dried over Linde Molecular Sieve No. 5A and fractionated through a Vigreaux column at atmospheric pressure (b. p. $129^{\circ}$ ).

Two amidations using the labeled benzoyl chloride were run in the 
following manner:

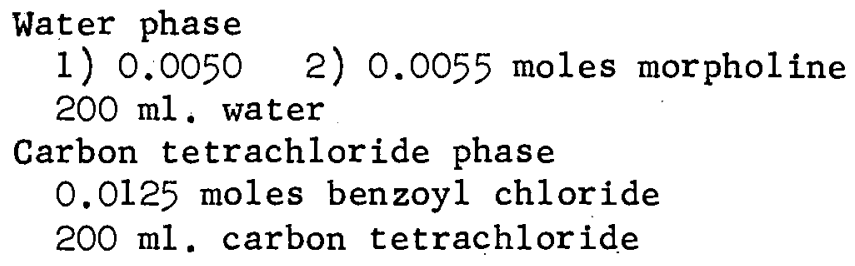

The reactions were stopped after 90 minutes. The amides were recovered as described above. The melting point of each sample of amide was $75^{\circ}$. The labeled benzoyl chloride not used in these amidations was converted to benzoic acid by hydrolyzing with a 100 per cent excess of 50 per cent sodium hydroxide solution, acidifying with hydrochloric acid, extracting three times with ether, and evaporating the ether. A bottle containing the benzoyl chloride and sodium hydroxide solution was placed on an automatic shaker for 24 hours. The yield of benzoic acid based on benzoyl chloride was 98.7 per cent. The melting point was $121.5-$ $122.0^{\circ}$. 


\section{RESULTS}

\section{Intrinsic Viscosities.}

Table I shows the intrinsic viscosities of polyamides and polyesters prepared from equimolar amounts of phthaloyl chloride and piperazine and of phthaloyl chloride and 4,4'-isopropylidene diphenol, respectively. Figure 1 (Polymer L) illustrates the determination of a typical intrinsic viscosity obtained by extrapolation of the specific viscosity to infinite dilution. In all cases the determinations were made at $26.62 \pm 0.02^{\circ}$ in $\underline{m}^{-c r e s o l}$.

Hydrolysis of Phthaloyl Chloride and Benzoyl Chloride.

The extent of phthaloyl chloride and benzoyl chloride hydrolysis occurring under conditions similar to those that would be encountered in interfacial polyamidation, polyesterification, and monoamidation is shown in Table.II, Table III, and Table IV.

\section{Kinetics of Polyamidation.}

The results obtained in the study of polyamidation at $0^{\circ}, 30^{\circ}$, and $50^{\circ}$ are contained in Table $\mathrm{V}$ and Table VI. In Table $\mathbf{V} \underline{\mathrm{n}}$ is the extent of polymerization." This is the convention adapted by. Flory (12) in his polycondensation kinetic studies. In Figure 2 these data are pIotted as second-order reactions. The original plots on large graph paper clearly show that the polyamidation at $0^{\circ}$ follows second-order kinetics 
TABLE I

INTRINSIC VISCOSITIES OF POLYAMIDES AND POLYESTERS

\begin{tabular}{lccc}
\hline Polymer & $\begin{array}{c}\text { Reaction } \\
\text { Temp. }\end{array}{ }^{\circ} \mathrm{C}$ & $\begin{array}{c}\text { Extent of } \\
\text { Polymerization }\end{array}$ & {$[\eta]$} \\
\hline Polyamide(L) & 0 & 0.936 & 4.14 \\
Polyamide(XXXIII) & 0 & 0.182 & 4.94 \\
Polyamide(LIV) & 30 & 0.111 & 2.11 \\
Polyamide(CVI) & 30 & 0.896 & 2.35 \\
Polyamide(LX) & 50 & 0.181 & 1.08 \\
Polyamide(XCIX) & 50 & 0.900 & 0.92 \\
Polyester(LXXXIX) & 0 & 0.139 & 0.88 \\
Polyester(XCII) & 0 & 0.977 & 0.85 \\
Polyester(C) & 30 & 0.268 & 0.69 \\
Polyester(CV) & 30 & 0.937 & 0.62 \\
Polyester(XCIII) & 50 & 0.355 & 0.58 \\
Polyester(XCVIII) & 50 & 0.934 & 0.55 \\
& & & \\
\hline
\end{tabular}




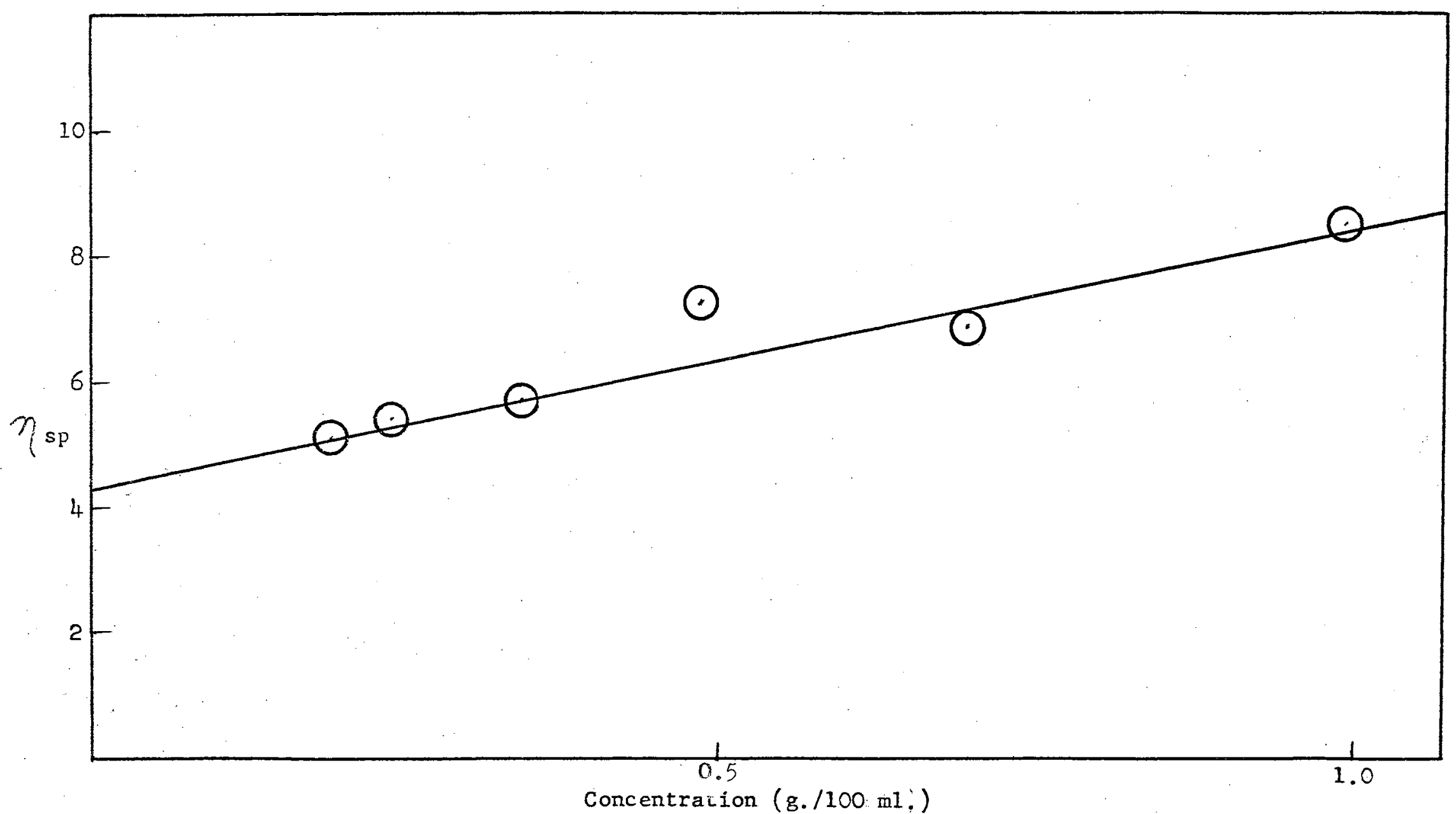

Figure 1. Intrinsic Viscosity of Polymer L 
TABLE II

HYDROLYSIS OF PHTHALOYL CHLORIDE IN POLYAMIDATION

\begin{tabular}{cccc}
\hline Sample & $\begin{array}{c}\text { Reaction Time, } \\
\text { min. }\end{array}$ & $\begin{array}{c}\text { AgCl } \\
\text { g. }\end{array}$ & $\begin{array}{c}\text { Extent of } \\
\text { Hydrolysis }\end{array}$ \\
\hline F & 3 & 0.0033 & 0.0018 \\
B & 8 & 0.0026 & 0.0014 \\
E & 29 & 0.0073 & 0.0056 \\
D & 131 & 0.0143 & 0.0080 \\
G & 360 & 0.0198 & 0.0110 \\
C & 614 & 0.0200 & 0.0112 \\
H & 840 & 0.0209 & 0.0117 \\
\end{tabular}

TABLE III

HYDROLYSIS OF PHTHALOYL CHLORIDE IN POLYESTERIFICATION

\begin{tabular}{cccc}
\hline Sample & $\begin{array}{c}\text { Reaction Time, } \\
\text { min. }\end{array}$ & $\begin{array}{c}\text { ggC1 } \\
\text { g. }\end{array}$ & $\begin{array}{c}\text { Extent of } \\
\text { Hydrolysis }\end{array}$ \\
\hline 1 & 1.3 & 0.0012 & 0.0007 \\
2 & 2.8 & 0.0025 & 0.0014 \\
3 & 6.5 & 0.0124 & 0.0069 \\
6 & 15.0 & 0.0243 & 0.0136 \\
5 & 76.0 & 0.0723 & 0.0403 \\
4 & 190.0 & 0.0735 & 0.0410 \\
8 & 455.0 & 0.0783 & 0.0437 \\
7 & 840.0 & 0.0767 & 0.0428 \\
\hline
\end{tabular}


TABLE IV

HYDROLYSIS OF BENZOYL CHLORIDE IN MONOAMIDATION

\begin{tabular}{lccc}
\hline Sample & $\begin{array}{c}\text { Reaction Time, } \\
\text { min. }\end{array}$ & $\begin{array}{c}\text { AgCl } \\
\text { g. }\end{array}$ & $\begin{array}{c}\text { Extent of } \\
\text { Hydrolysis }\end{array}$ \\
B-1 & 3 & 0.0196 & 0.0109 \\
B-2 & 20 & 0.0420 & 0.0234 \\
B-3 & 120 & 0.3128 & 0.175 \\
\hline
\end{tabular}


TABLE V

POLYAMIDATION KINETIC DATA

\begin{tabular}{|c|c|c|c|c|}
\hline $\begin{array}{l}\text { Reaction } \\
\text { Time, min. }\end{array}$ & $\begin{array}{l}\text { Reaction } \\
\text { Temp., }{ }^{\circ} \mathrm{C} .\end{array}$ & $\begin{array}{c}\text { Polymer, } \\
\text { g. }\end{array}$ & $\begin{array}{c}\text { Extent of } \\
\text { Polymerization, } \\
\text { n }\end{array}$ & $\frac{1}{1-n}$ \\
\hline 0.25 & 0 & 0.4480 & 0.180 & 1.22 \\
\hline 1 & 0 & 0.4911 & 0.182 & 1.22 \\
\hline 4 & 0 & 0.5855 & 0.217 & 1.28 \\
\hline 20 & 0 & 1.1523 & 0.426 & 1.74 \\
\hline 60 & 0 & 1.7543 & 0.649 & 2.85 \\
\hline 120 & 0 & 2.1151 & 0.782 & 4.60 \\
\hline 240 & 0 & 2.3794 & 0.880 & 8.35 \\
\hline 360 & 0 & 2.4854 & 0.919 & 12.42 \\
\hline 480 & 0 & 2.5301 & 0.936 & 15.64 \\
\hline 600 & 0 & 2.5603 & 0.947 & 18.94 \\
\hline 720 & 0 & 2.5843 & 0.956 & 22.78 \\
\hline 3 & 30 & 0.3014 & 0.111 & 1.12 \\
\hline 9 & 30 & 0.7571 & 0.280 & 1.39 \\
\hline 15 & 30 & 1.0020 & 0.371 & 1.59 \\
\hline 21 & 30 & 1.2228 & 0.452 & 1.83 \\
\hline 30 & 30 & 1.5128 & 0.600 & 2.27 \\
\hline 90 & 30 & 2.0951 & 0.775 & 4.45 \\
\hline 120 & 30 & 2.2043 & 0.815 & 5.42 \\
\hline 230 & 30 & 2.3927 & 0.885 & 8.71 \\
\hline 300 & 30 & 2.4218 & 0.896 & 9.61 \\
\hline 3 & 50 & 0.4895 & 0.181 & 1.22 \\
\hline 9 & 50 & 0.8012 & 0.296 & 1.42 \\
\hline
\end{tabular}


TABLE V (Continued)

\begin{tabular}{ccccc}
\hline $\begin{array}{l}\text { Reaction } \\
\text { Time, min. }\end{array}$ & $\begin{array}{c}\text { Reaction } \\
\text { Temp. }{ }^{\circ} \mathrm{C} .\end{array}$ & $\begin{array}{c}\text { Polymer, } \\
\text { g. }\end{array}$ & $\begin{array}{c}\text { Extent of } \\
\text { Polymerization, } \\
\text { n }\end{array}$ & $\frac{1}{1-\mathrm{n}}$ \\
\hline 15 & 50 & 1.0363 & 0.383 & 1.62 \\
21 & 50 & 1.2988 & 0.480 & 1.92 \\
30 & 50 & 1.5472 & 0.572 & 2.34 \\
70 & 50 & 2.0634 & 0.763 & 4.23 \\
120 & 50 & 2.2548 & 0.834 & 6.03 \\
230 & 50 & 2.4200 & 0.895 & 9.55 \\
303 & 50 & 2.4340 & 0.900 & 10.05 \\
& & & & \\
\hline
\end{tabular}




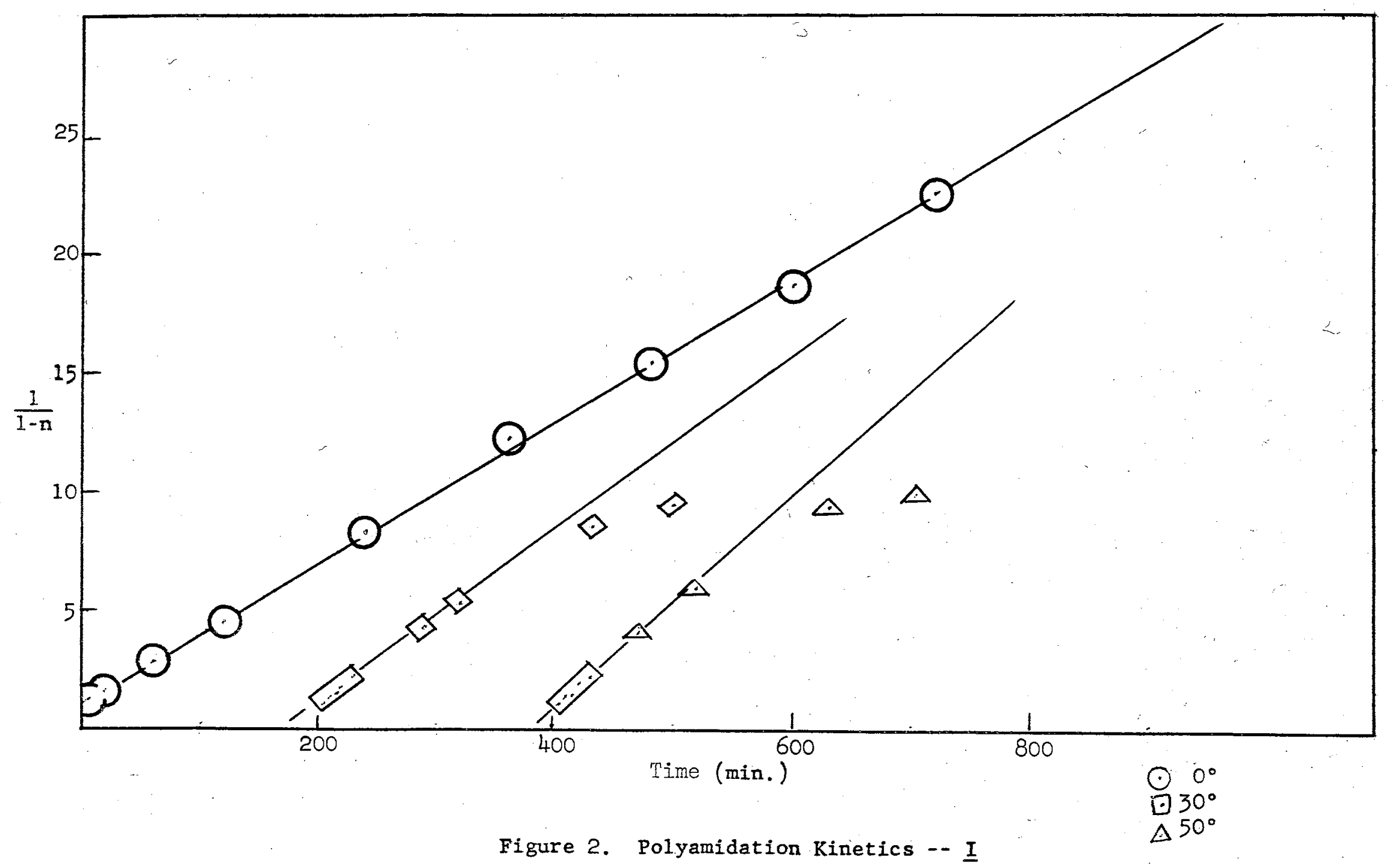




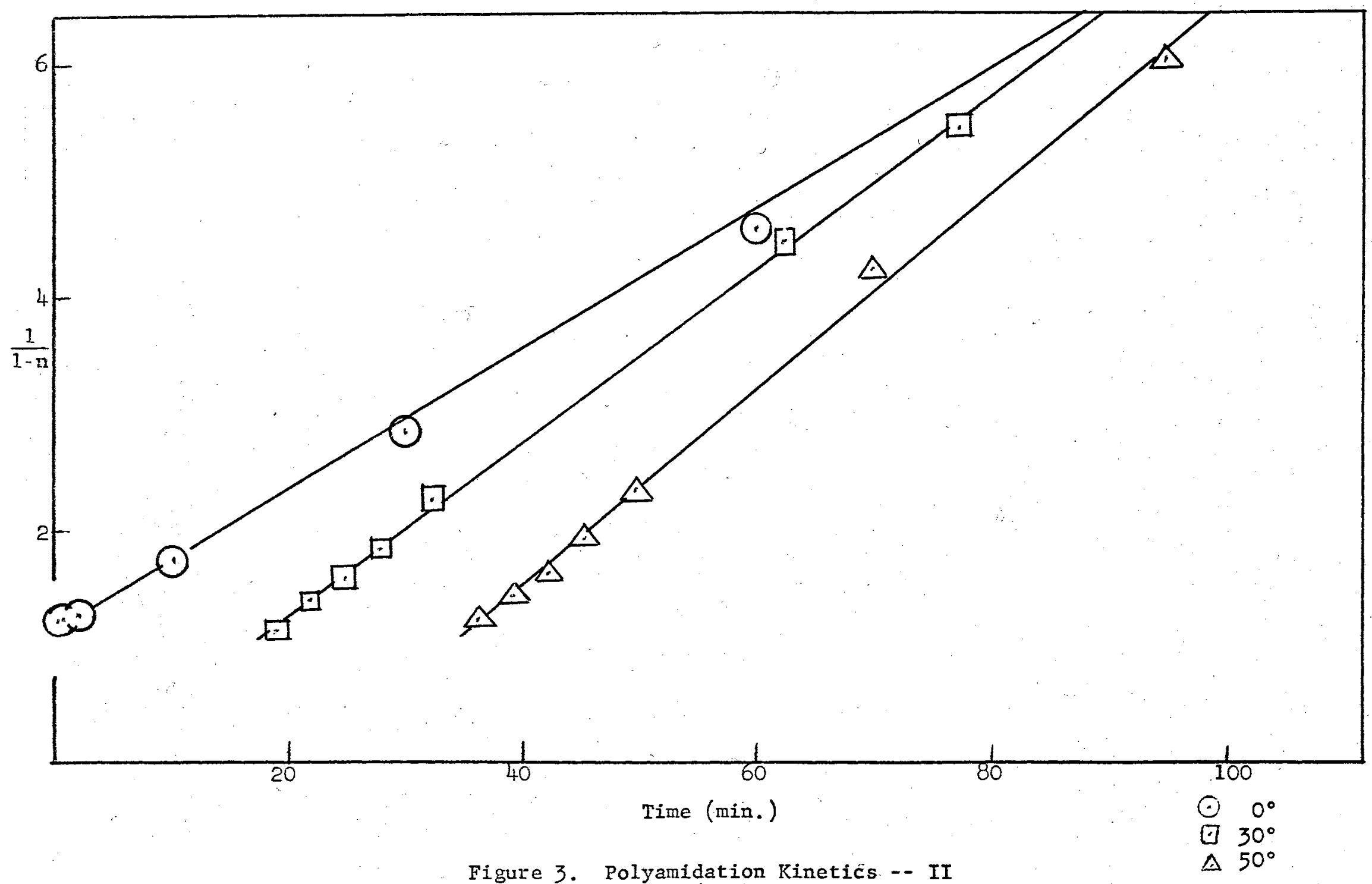




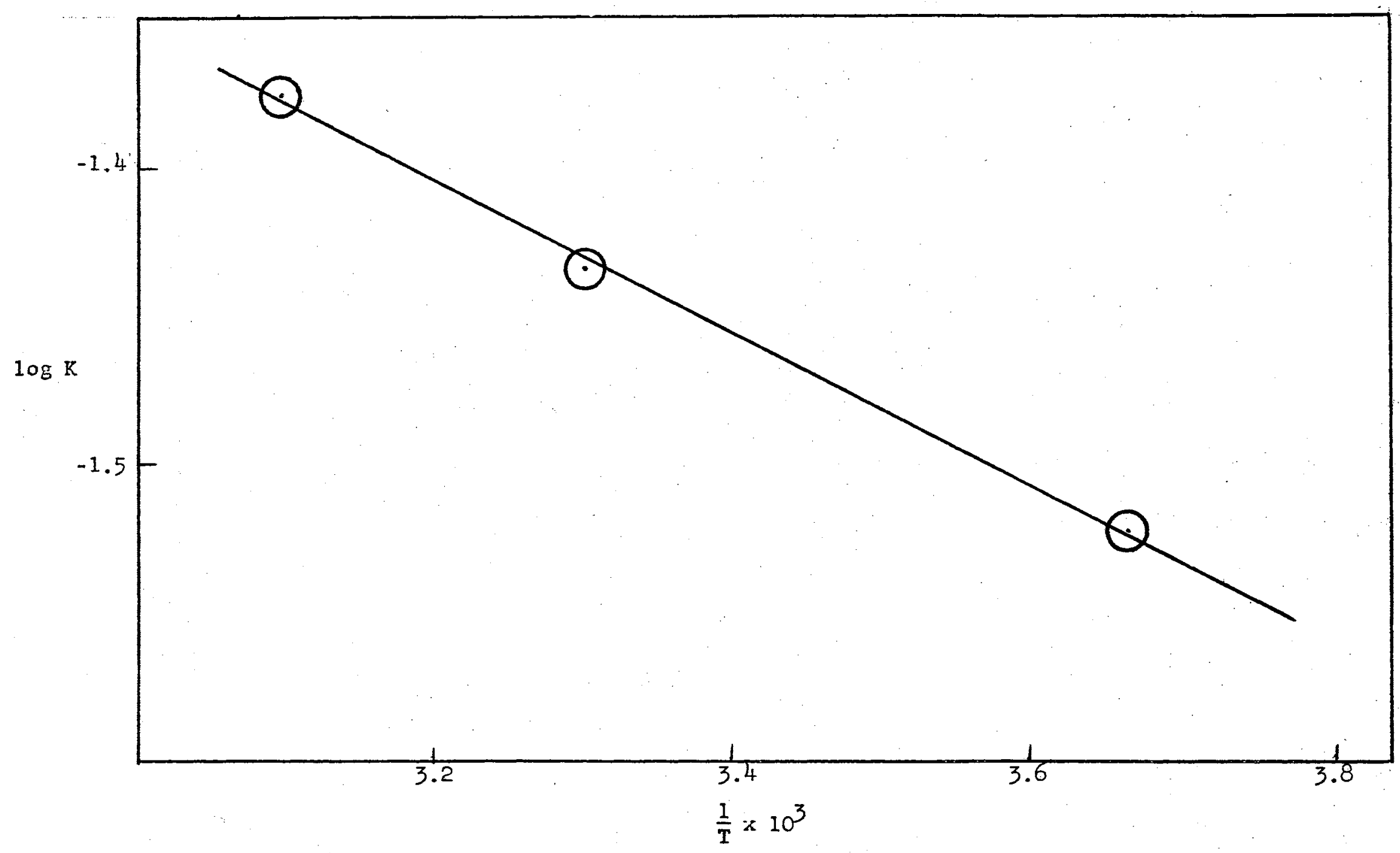

Figure 4. Apparent Polyamidation Activation Energy 
throughout the course of the reaction; however, the rates of the $30^{\circ}$ and $50^{\circ}$ polyamidation reactions decrease beyond $80-85$ per cent conversion. Figure 3 contains the initial portions of the original large scale plots. The method of least squares (9) was used in plotting the data. Table VI lists the rate constants obtained from the slopes of the lines in Figure 2 and the apparent activation energy obtained from the slope of the line in Figure 4. The line in Figure 4 was drawn by the least squares method.

\section{TABLE VI}

POLYAMIDATION RATE CONSTANTS AND APPARENT ACTIVATION ENERGY

\begin{tabular}{ccc}
\hline $\begin{array}{c}\text { Rate Constant, } \\
\text { mole }^{-1} \text { min }^{-1}\end{array}$ & $\begin{array}{c}\text { Temperature, } \\
{ }^{\circ} \mathrm{K}\end{array}$ & $\begin{array}{c}\text { Activation Energy, } \\
\text { cal. mole } \mathrm{mol}^{-1}\end{array}$ \\
\hline 0.0300 & 273 & \\
0.0369 & 303 & 1180 \\
0.0422 & 323 &
\end{tabular}

\section{Kinetics of Polyesterification.}

The results of the series of polyesterification reactions are given in Table VII and Table VIII. The course of the polyesterification reactions closely parallels the polyamidation reactions. The $0^{\circ}$ polyesterification remains second order throughout the course of the reaction, and the rates of the reactions at $30^{\circ}$ and $50^{\circ}$ decrease at 88-90 per cent reaction. Figure 5 includes the initial portions of the original plots and Figure 6 is a small scale reproduction of the original plots. The $0^{\circ}$ line and the lines connecting the initial seven points of the $30^{\circ}$ and $50^{\circ}$ reactions were plotted according to the method of least squares. The 
TABLE VII

KINETICS OF POLYESTERIFICATION

\begin{tabular}{|c|c|c|c|c|}
\hline $\begin{array}{l}\text { Reaction } \\
\text { Time. min. }\end{array}$ & $\begin{array}{l}\text { Reaction } \\
\text { Temp., }{ }^{\circ} \mathrm{C} \text {. }\end{array}$ & $\begin{array}{c}\text { Polymer, } \\
\text { g. }\end{array}$ & $\begin{array}{c}\text { Extent of } \\
\text { Polymerization, } \\
n\end{array}$ & $\frac{1}{1+n}$ \\
\hline 0.25 & 0 & 0.6213 & 0.139 & 1.16 \\
\hline 0.75 & 0 & 1.6660 & 0.372 & 1.59 \\
\hline 3 & 0 & 1.6991 & 0.379 & 1.61 \\
\hline 15 & 0 & 2.1207 & 0.473 & 1.90 \\
\hline 50 & 0 & 3.2289 & 0.721 & 3.58 \\
\hline 90 & 0 & 3.7965 & 0.847 & 6.56 \\
\hline 150 & 0 & 3.9399 & 0.879 & 8.30 \\
\hline 210 & 0 & 4.0850 & 0.920 & 11.35 \\
\hline 300 & 0 & 4.1854 & 0.934 & 15.22 \\
\hline 600 & 0 & 4.3345 & 0.968 & 30.86 \\
\hline 900 & 0 & 4.3784 & 0.977 & 44.25 \\
\hline 3 & 30 & 1.2019 & 0.268 & 1.37 \\
\hline 9 & 30 & 1.5075 & 0.336 & 1.51 \\
\hline 15 & 30 & 2.1410 & 0.478 & 1.91 \\
\hline 21 & 30 & 2.6417 & 0.590 & 2.44 \\
\hline 30 & 30 & 2.8137 & 0.628 & 2.69 \\
\hline 90 & 30 & 3.8588 & 0.861 & 6.30 \\
\hline 120 & 30 & 3.9211 & 0.875 & 8.02 \\
\hline 230 & 30 & 4.1495 & 0.926 & 13.57 \\
\hline 300 & 30 & 4.1979 & 0.937 & 15.90 \\
\hline 3 & 50 & 1.5899 & 0.355 & 1.55 \\
\hline 9 & 50 & 1.9911 & 0.444 & 1.80 \\
\hline
\end{tabular}


TABLE VII (Continued)

\begin{tabular}{ccccc}
\hline $\begin{array}{l}\text { Reaction } \\
\text { Time, min. }\end{array}$ & $\begin{array}{c}\text { Reaction } \\
\text { Temp., }{ }^{\circ} \mathrm{C}\end{array}$ & $\begin{array}{c}\text { Polymer, } \\
\text { g. }\end{array}$ & $\begin{array}{c}\text { Extent of } \\
\text { Polymerization, } \\
\text { n }\end{array}$ & $\frac{1}{1-\mathrm{n}}$ \\
\hline 15 & 50 & 2.4131 & 0.539 & 2.17 \\
21 & 50 & 2.6412 & 0.590 & 2.44 \\
30 & 50 & 3.0484 & 0.680 & 3.13 \\
70 & 50 & 3.7092 & 0.828 & 5.81 \\
120 & 50 & 3.9757 & 0.887 & 8.89 \\
230 & 50 & 4.1567 & 0.928 & 13.87 \\
300 & 50 & 4.1854 & 0.934 & 15.22 \\
& & & & \\
\hline
\end{tabular}




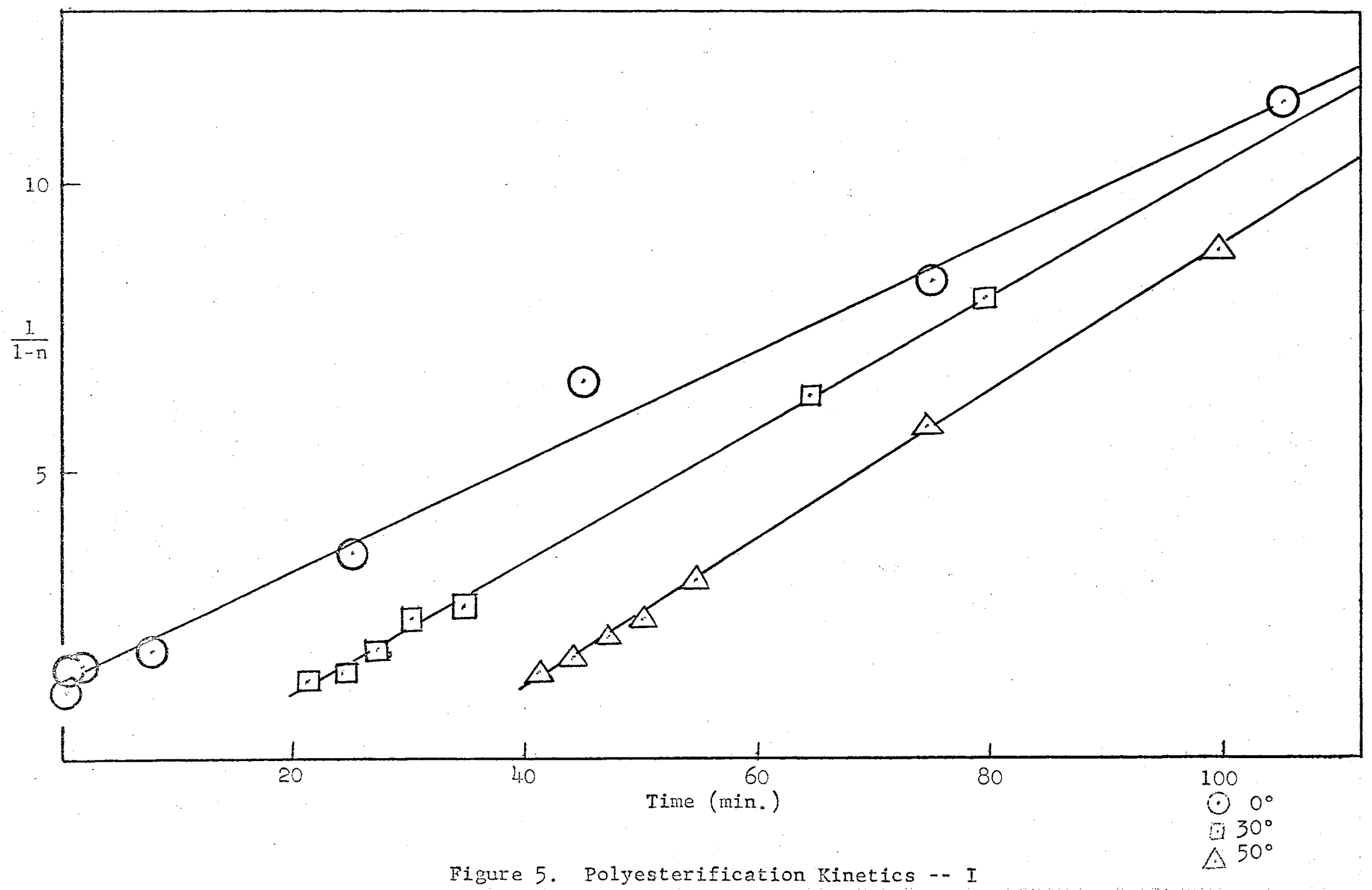




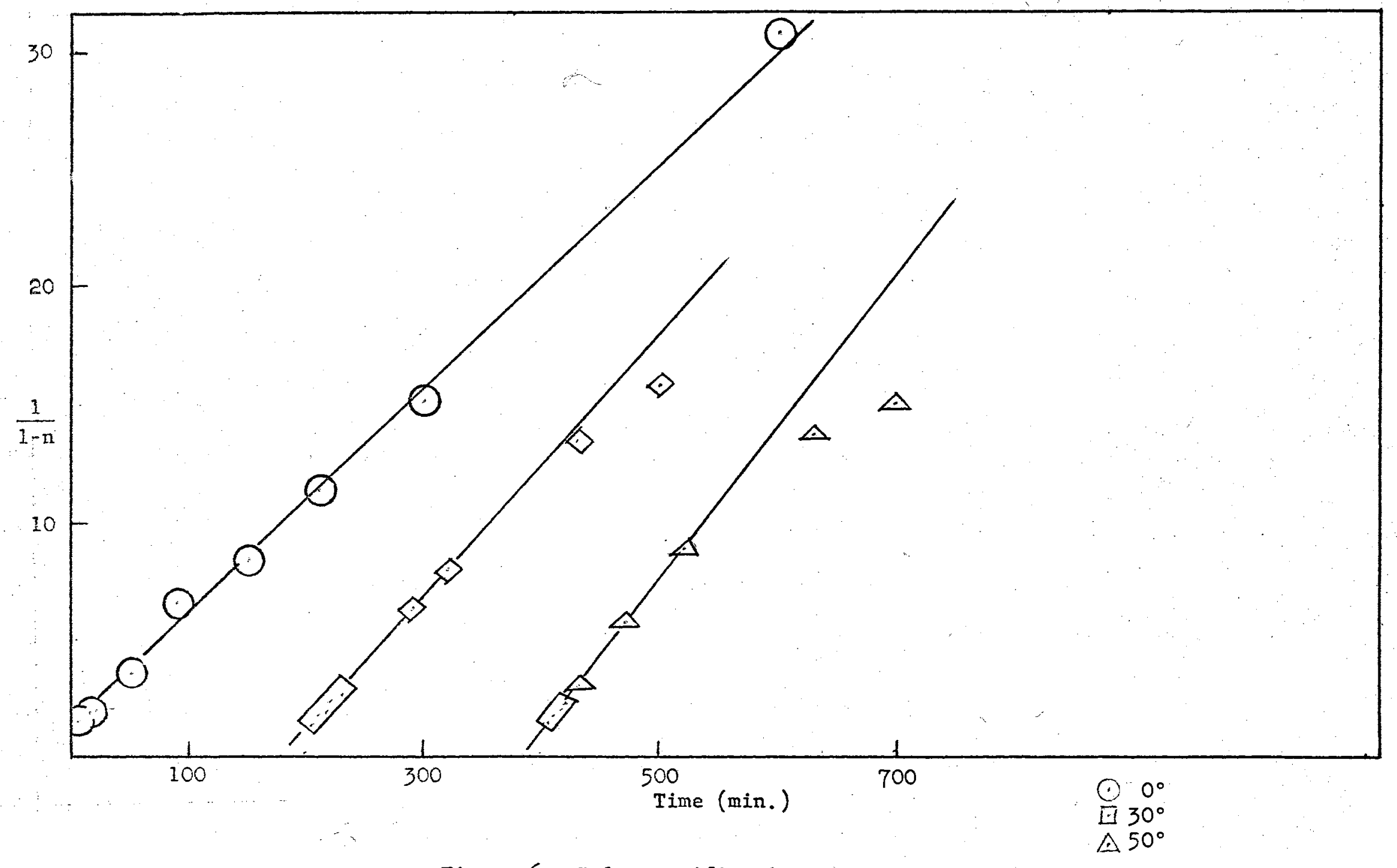

Figure 6. Polyesterification Kinetics -- II 


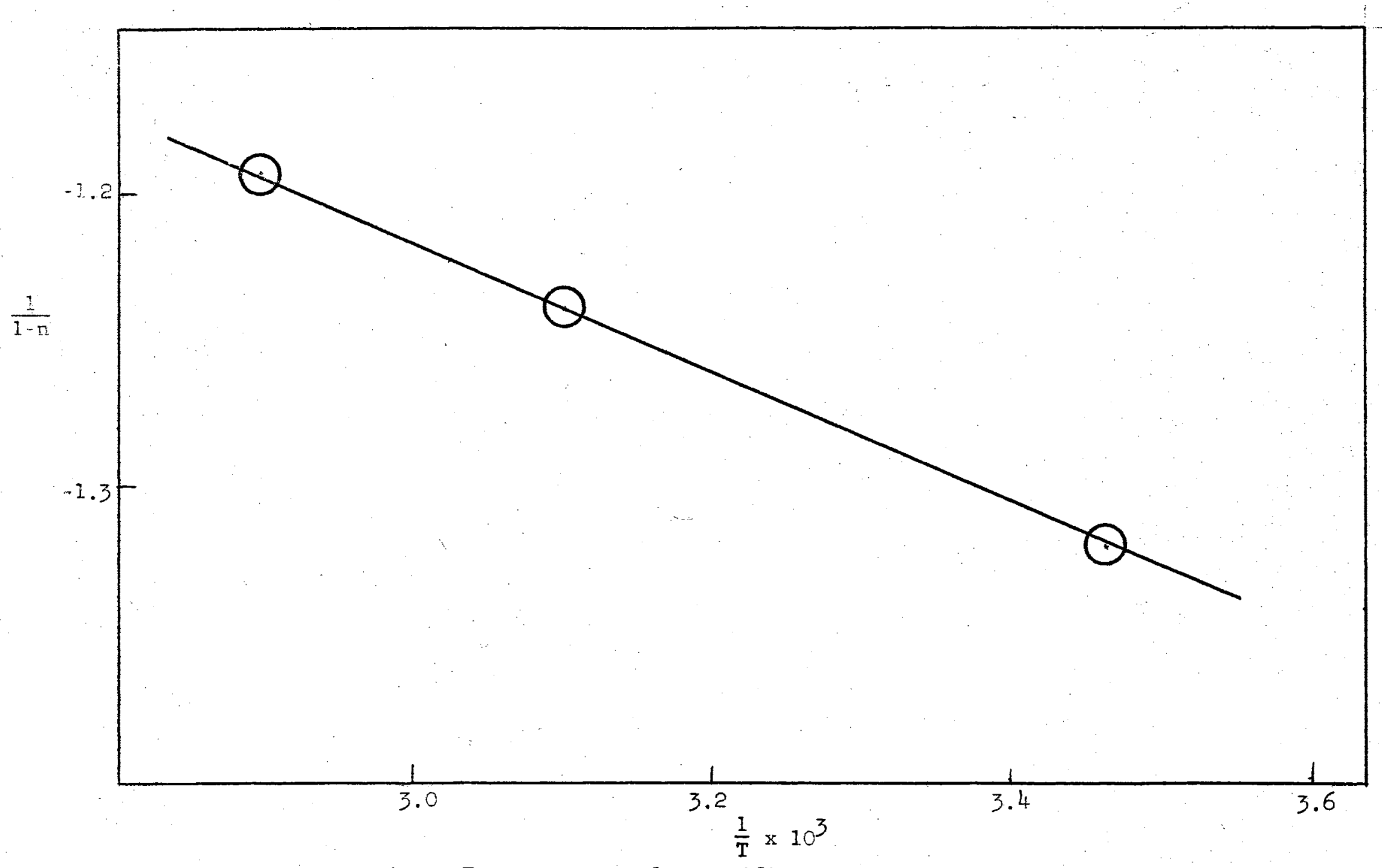

Figure 7. Apparent Polyesterification Activation Energy 
rate constants and the apparent activation energy are given in Table VIII. The apparent activation energy was obtained from the slope of the line in Figure 7.

TABLE VIII

POLYESTERIFICATION RATE CONSTANTS AND APPARENT ACTIVATION ENERGY

\begin{tabular}{ccc}
\hline $\begin{array}{c}\text { Rate Constant, } \\
\text { mole }{ }^{-1} \text { min. }{ }^{-1}\end{array}$ & $\begin{array}{c}\text { Temperature, } \\
{ }^{\circ} \mathrm{K}\end{array}$ & $\begin{array}{c}\text { Activation Energy, } \\
\text { cal. mole } \text { m }^{-1}\end{array}$ \\
\hline 0.0480 & 273 & \\
0.0577 & 303 & 1010 \\
0.0640 & 323 & \\
\hline
\end{tabular}

Monomer Diffusion Studies.

Polyamidation at Varying Monomer Ratios: The results of varying the phthaloyl chloride/piperazine ratio are shown in Table IX. The two series of monomer ratios are plotted as second-order reactions in Figure 8. The rate constants obtained from the plots in Figure 8 are given in Table X.

Polyesterification at Varying Monomer Ratios: The data obtained by varying the phthaloyl chloride/4, 4'-isopropylidene diphenol ratio are given in Table XI. The two series of monomer ratios are plotted as second-order reactions in Figure 9. The rate constants obtained from the plots in Figure 9 are listed in Table XII.

Piperazine and 4,4'-isopropylidene Diphenol Migration: Table XIII contains the results of the series of experiments dealing with the migration of piperazine and 4,4'-isopropylidene diphenol from basic aqueous solutions into carbon tetrachloride. 


\section{TABLE IX}

\section{POLYAMIDATION AT VARYING MONOMER RATIOS}

Reaction Temperature, $0^{\circ}$

\begin{tabular}{|c|c|c|c|c|}
\hline $\begin{array}{l}\text { Moles phthaloyl chloride } \\
\text { Moles piperazine }\end{array}$ & $\begin{array}{l}\text { Reaction } \\
\text { Time, min. }\end{array}$ & {$[\eta]$} & $\begin{array}{l}\text { Extent of Poly- } \\
\text { merization, } n\end{array}$ & $\frac{1}{1-n}$ \\
\hline \multirow[t]{5}{*}{$1 / 5$} & 0.33 & 4.13 & 0.066 & 1.07 \\
\hline & 1 & & 0.069 & 1.07 \\
\hline & 6 & & 0.152 & 1.18 \\
\hline & 30 & 4.35 & 0.386 & 1.63 \\
\hline & 90 & & 0.638 & 2.76 \\
\hline \multirow[t]{5}{*}{$5 / 1$} & 0.33 & 4.22 & 0.037 & 1.04 \\
\hline & 1 & & 0.042 & 1.04 \\
\hline & 6 & & 0.098 & 1.11 \\
\hline & 30 & 4.04 & 0.311 & 1.45 \\
\hline & 90 & & 0.542 & 2.19 \\
\hline
\end{tabular}

TABLE $X$

POLYAMIDATION RATE CONSTANTS AT VARYING MONOMER RATIOS

Reaction Temperature, $0^{\circ}$

\begin{tabular}{cc}
\hline Moles phthaloyl chloride & $\begin{array}{c}\text { Reaction Rate Constant, } \\
\text { mole } \mathrm{e}^{-1} \text { min }^{-1}\end{array}$ \\
\hline $1 / 5$ & 0.0189 \\
$5 / 1$ & 0.0129 \\
\hline
\end{tabular}




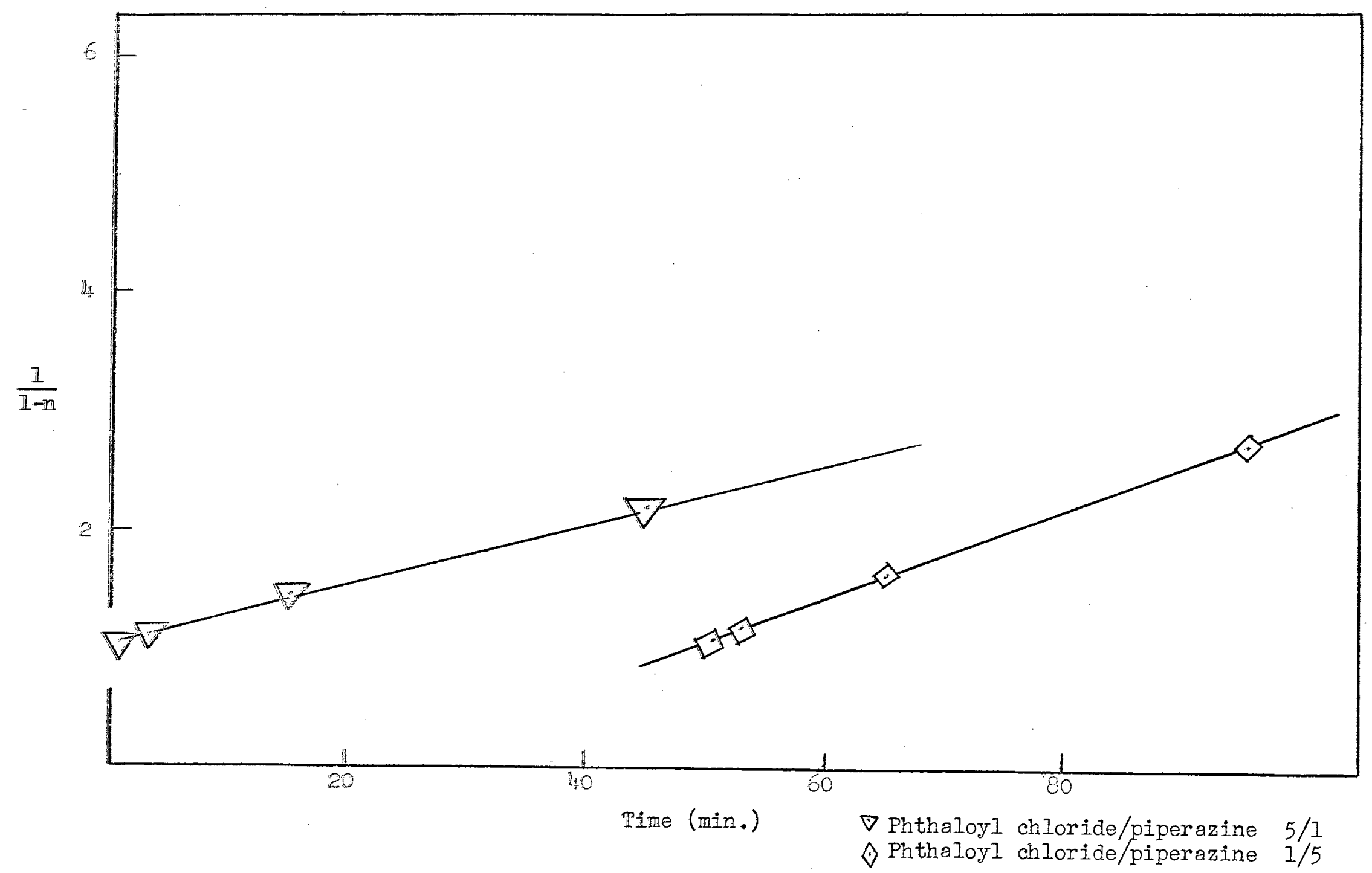

Figure 8. Polyamidation at Varying Monomer Ratios 
TABLE XI

POLYESTERIFICATION AT VARYING MONOMER RATIOS

Reaction Temperature, $0^{\circ}$

\begin{tabular}{|c|c|c|c|c|}
\hline $\begin{array}{l}\text { Moles phthatoy } 1 \text { chloride } \\
\text { Moles diphenol }\end{array}$ & $\begin{array}{l}\text { Reaction } \\
\text { Time, min. }\end{array}$ & {$[m]$} & $\begin{array}{c}\text { Extent of } \\
\text { Polymerization, } \\
n\end{array}$ & $\frac{1}{1-n}$ \\
\hline \multirow[t]{5}{*}{$5 / 1$} & 0.33 & 0.78 & 0.040 & 1.04 \\
\hline & 1 & & 0.079 & 1.09 \\
\hline & 6 & & 0.240 & 1.32 \\
\hline & 30 & 0.66 & 0.505 & 2.02 \\
\hline & 100 & 0.87 & 0.776 & 4.47 \\
\hline \multirow[t]{5}{*}{$1 / 5$} & 0.33 & 0.83 & 0.076 & 1,08 \\
\hline & 1 & & 0.090 & 1.10 \\
\hline & 6 & & 0.165 & 1.20 \\
\hline & 30 & 0.84 & 0.546 & 2.20 \\
\hline & 90 & & 0.770 & 4.34 \\
\hline
\end{tabular}

TABLE XII

POLYESTERIFICATION RATE CONSTANTS AT VARYING MONOMER RATIOS

Moles phthaloyl chloride

Moles diphenol

Rate Constant, mole $e^{-1} \min ^{-1}$

$5 / 1$

0.0340

$1 / 5$

0.0367 


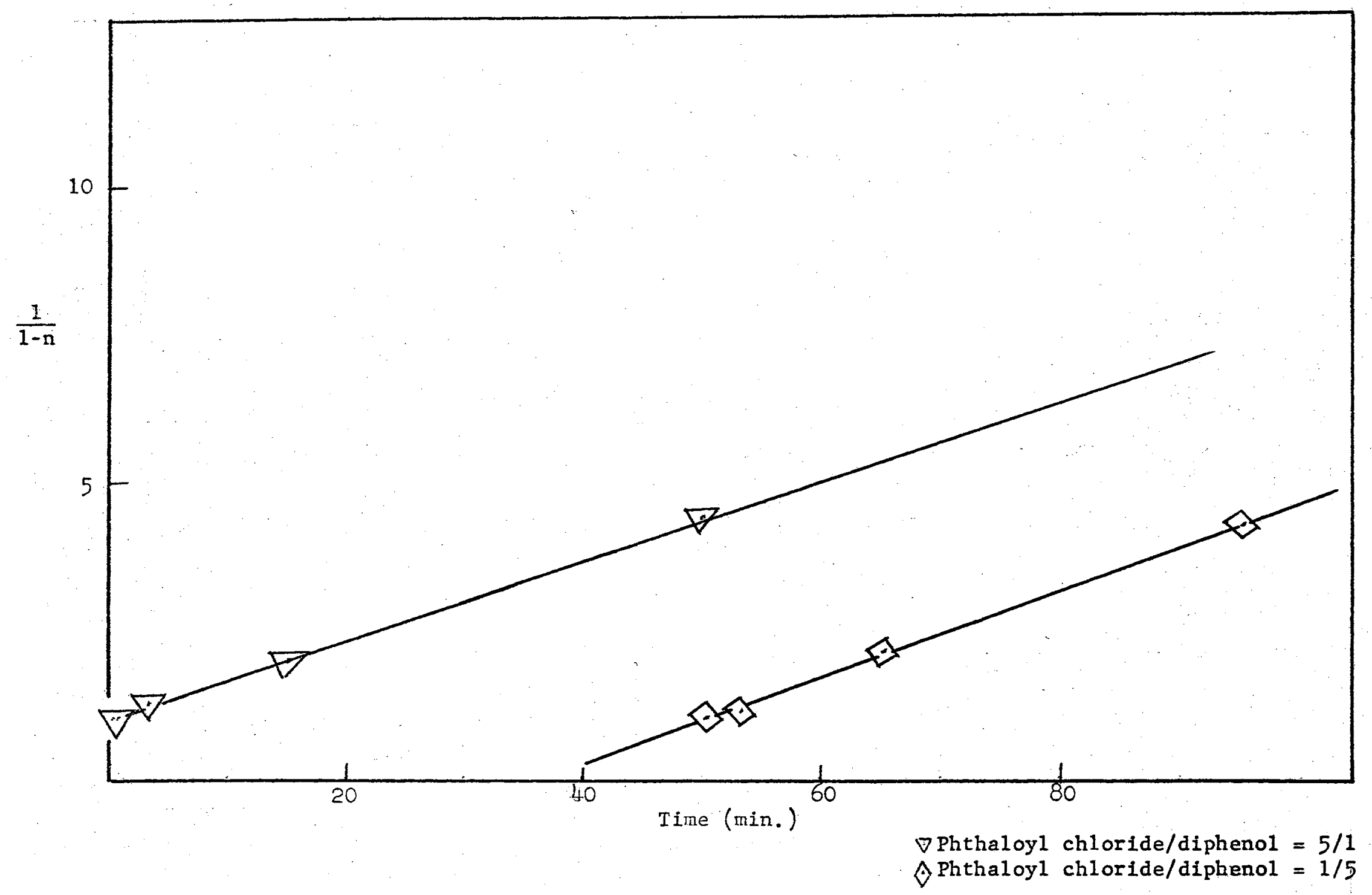

Figure 9. Polyesterification at Varying Monomer Ratios 
TABLE XIII

MONOMER MIGRATION INTO CARBON TETRACHLORIDE

\begin{tabular}{lcc}
\hline Monomer & Migration Time, min. & Migration, \% \\
\hline Piperazine & 3 & 6.31 \\
& 20 & 6.41 \\
& 60 & 6.66 \\
Diphenol & 3 & 2.51 \\
& 20 & 2.86 \\
& 60 & 2.82 \\
\hline
\end{tabular}


Experimental Carbon-14 Isotope Effect in Polyamidation.

The radioactivity assays and isotope effect for the samples of polymers from polyamidation reactions at $0^{\circ}$ are given in Table XIV. The specific activities were averaged and 95 per cent confidence levels of the means were determined using the student-t distribution (40).

Experimental Carbon-14 Isotope Effect in Polyesterification.

The radioactivity assays and isotope effect for the samples of polymers from polyesterification at $0^{\circ}$ are given in Table XV.

Experimental Carbon-14 Isotope Effect in Monoamidation.

The radioactivity assays and isotope effect for the samples of products from the $0^{\circ}$ monoamidation reaction between morpholine and benzoyl chloride are shown in Table XVI. 
TABLE XIV

ISOTOPE EFFECT IN POLYAMIDATION

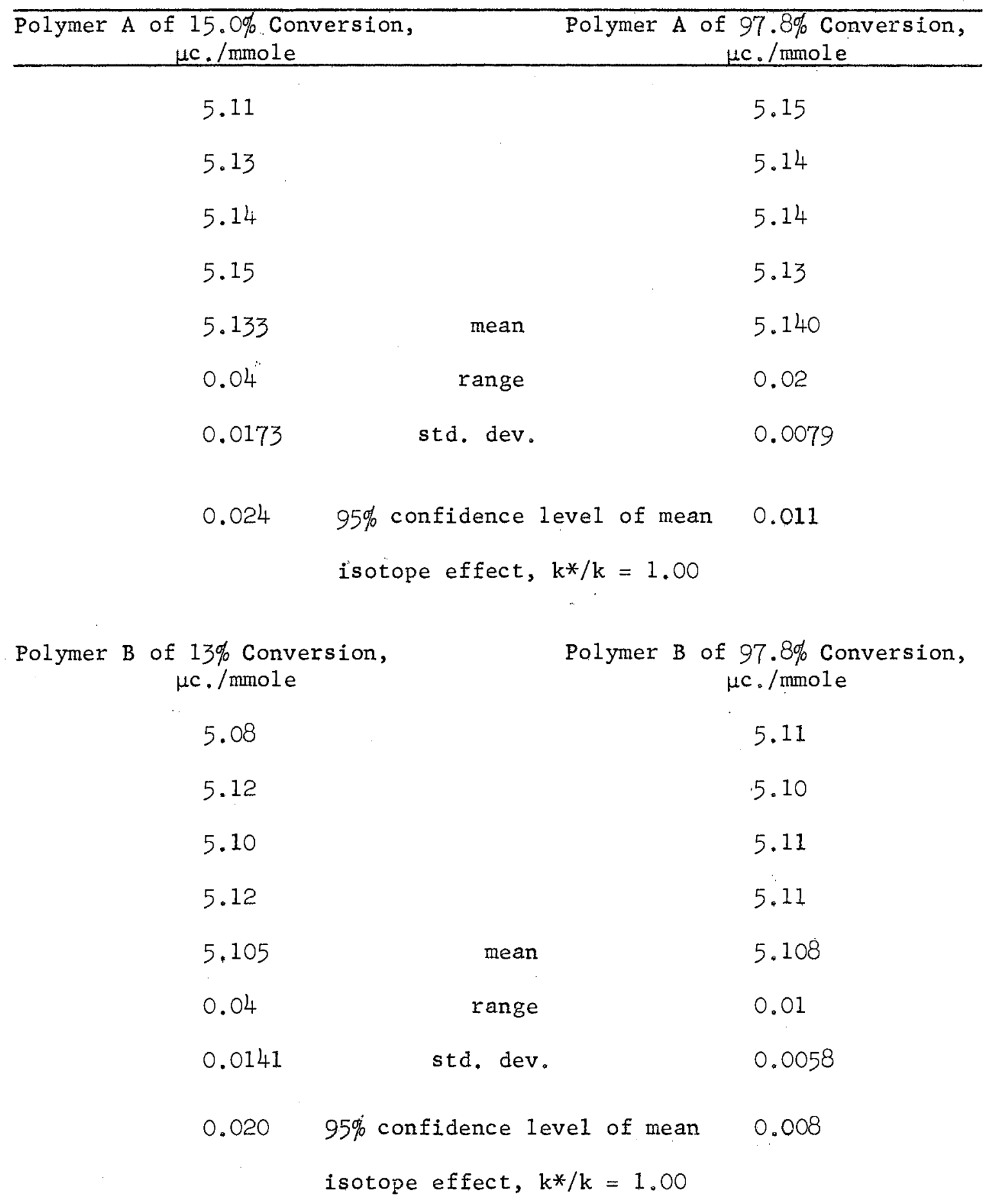


TABLE XV

\section{ISOTOPE EFFECT IN POLYESTERIFICATION}

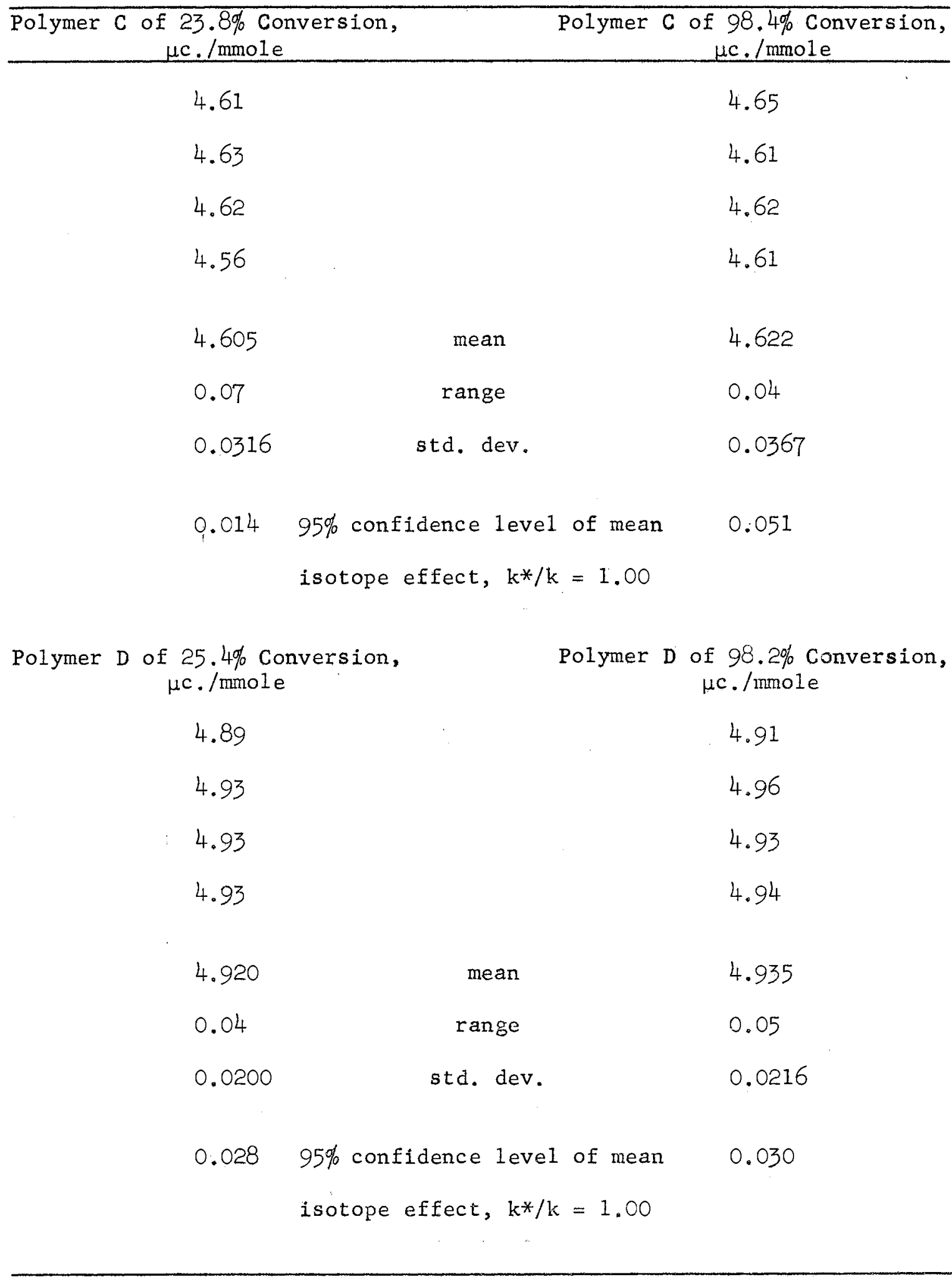


TABLE XVI

\section{ISOTOPE EFFECT IN MONOAMIDATION}

\begin{tabular}{|c|c|c|c|}
\hline$\overline{\text { Amide }}$ & $\begin{array}{r}\text { of } 14.9 \% \text { Conve } \\
\mu \mathrm{c} . / \mathrm{mmol} \\
\end{array}$ & Benzoyl $\mathrm{Cl}$ & $\begin{array}{l}\text { ride (Benzoic Acid), } \\
\mu \mathrm{c} \text {. /mmole }\end{array}$ \\
\hline & 3.55 & & 3.78 \\
\hline & 3.57 & & 3.78 \\
\hline & 3.59 & & 3.79 \\
\hline & 3.55 & & 3.77 \\
\hline & 3.565 & mean & 3.780 \\
\hline & 0.04 & range & 0.02 \\
\hline & 0.0200 & std, dev. & 0.0081 \\
\hline & 0.028 & $\begin{array}{l}95 \% \text { confidence level of mean } \\
\text { isotope effect, } k^{*} / k=0.937\end{array}$ & 0.011 \\
\hline Amide & $\begin{array}{r}\text { of } 21.4 \% \text { Conve } \\
\mu \mathrm{c} . / \mathrm{mmol}\end{array}$ & Benzoyl Cr & $\begin{array}{l}\text { Eide (Benzoic Acid), } \\
\mu \mathrm{c} \text { / /mnole }\end{array}$ \\
\hline & 3.64 & & 3.83 \\
\hline & 3.68 & & 3.79 \\
\hline & 3.67 & & 3.79 \\
\hline & 3.69 & & 3.76 \\
\hline & 3.670 & mean & 3.792 \\
\hline & 0.05 & range & 0.07 \\
\hline & 0.0216 & std, dev. & 0.0288 \\
\hline & 0.030 & $\begin{array}{l}95 \% \text { confidence level of mean } \\
\text { isotope effect, } k * / k=0.965\end{array}$ & 0.040 \\
\hline
\end{tabular}




\section{DISCUSSION OF RESULTS}

\section{Intrinsic Viscosity.}

The intrinsic viscosity determinations indicate that the molecular weight falls off rapidly as the temperature is increased in the polymerization reactions. Furthermore, large variations in the monomer/ monomer ratio do not appear to affect the molecular weight of the polymers. In all cases the molecular weight is the same at low and high extent of polymerization.

Hydrolys is of Phthaloyl Chloride and Benzoyl Chloride.

The results of the hydrolysis studies clearly indicate that the rates of hydrolysis of benzoyl chloride and phthaloyl chloride are negligible in comparison with the interfacial reactions of amidation, polyamidation, and polyesterification at $0^{\circ}$. As one raises the reaction temperature, however, hydrolysis may well become an important side reaction. An increase in the rate of hydrolysis would explain the decrease observed in the rates of polyesterification and polyamidation beyond $80-90$ per cent conversion at $30^{\circ}$ and $50^{\circ}$.

Kinetics of Polyamidation and Polyesterification.

As was discussed earlier, the kinetic data obtained in this work are dependent upon a number of variables, and caution must be exercised in discussing the final results. The rate constants are undoubtably 
dependent upon the rate of mixing; due to the changes in viscosity and the nature of the interface, the activation energy obtained must be considered an apparent activation energy.

The polyamidation and polyesterification reactions adhere closely to second-order kinetics; however, proving that the reactions are first order with respect to each monomer is difficult. Varying the ratio of one monomer to the other monomer resulted in a decrease in rate in both polyesterification and polyamidation. However, it must be remembered that the rate constants are based upon yields of precipitated polymers; and any dissolved or swollen polymer was not recovered.

\section{Carbon-14 Isotope Effects.}

It seems to be rather evident from the migration of piperazine and 4, 4'-isopropylidene diphenol from water into carbon tetrachloride that the amine and the alcohol are the migrating species in interfacial condensations. This fact is in line with the mechanism proposed by the du Pont researchers. This information coupled with the findings that hydrolysis of phthaloyl chloride is negligible in the condensations means that isotope effects in diffusion or hydrolysis may be neglected. The carbon-14 isotope effects appear to be, therefore, kinetic effects for polyamidation and polyesterification. 


\section{CONCLUS IONS}

From the facts gathered in this research an attempt can now be made to propose a reasonable mechanism for interfacial polyamidation and polyesterification. The first step appears to be migration of difunctional amine or alcohol from the aqueous phase into the carbon tetrachloride phase. It then appears that polymerization occurs in the organic solvent by means of a slow nucleophilic initiation step followed by a very fast propagation of the polymer chain until the chain reaches a high molecular weight in a rather narrow range. At this point the polymer precipitates; if an appropriate organic solvent is used in the reaction, the polymer may swell and settle out as a film at an unstirred interface.

The above mechanism appears to be consistent with the following facts:

1) Piperazine and 4, 4'-isopropylidene diphenol migrate rapid1y and to an appreciable extent from water into carbon tetrachloride. If phthaloyl chloride were the migrating agent, one should obtain an isotope effect due to diffusion in polyamidation and polyesterification.

2) Polyamidation and polyesterification both follow second-order kinetics.

3) The intrinsic viscosity of the polymer and hence its molecular weight remains essentially constant throughout the course of interfacial polyamidation and polyesterification.

4) The apparent activation energy for both polyamidation and polyesterification is extremely small. 
5) There is no detectable carbon-14 isotope effect in either polyamidation or polyesterification. Buist and Bender (6) have shown that a linear relationship between activation energy and the kinetic isotope effect is quite evident in a given family of reactions. Qualitatively one can say that a reaction with a very low activation energy should exhibit a very low isotope effect. Now the monoamidation reaction between morpholine and benzoyl chloride shows a definite carbon-14 isotope effect; however, a basic difference exists between interfacial monoamidation and interfacial polyamidation. The activation energy of monoamidation theoretically should remain constant throughout the reaction. Interfacial polyamidation apparently has an initiation activation energy and a much smaller chain propagation activation energy (or energies). This assumption is born out by the fact that high molecular weight polymer is formed immediately in the reaction. If the activation energies of initiation and propagation were of the same order, one would obtain high molecular weight polymer only at high extent of reaction. The molecular weight would increase with the extent of reaction as dimers, trimers, tetramers, etc. are slowly converted to long chains.

6) When the monomer $A$ /monomer $B$ ratio is increased from $1 / 1$ to $5 / 1$ or decreased from $1 / 1$ to $1 / 5$ the polymerization rate is decreased. At any time $\underline{t}$ one obtains more precipitated polymer when one starts with one mole of monomer $\mathrm{A}$ and one mole of monomer $\mathrm{B}$ than when one starts with 5 moles of monomer A (or monomer B) and one mole of monomer B (or monomer A). This indicates that the polymers precipitate within a narrow high molecular weight range, leaving lower molecular weight polymer dissolved in the organic solvent.

The mechanism of polymerization suggested by the du Pont workers 
is consistent with the results obtained in this research; however, the du Pont workers did not mention any kinetic data or molecular weight studies in their published work.

Unfortunately, the author cannot theoretically account for the observation that the intrinsic viscosity of the polymers decreased drastically as the temperature was increased. To correlate this fact with the proposed mechanism, one would have to assume that the solubility of the polymers in carbon tetrachloride is decreased with increasing temperature. This would enable the polymer to precipitate from carbon tetrachloride at a lower molecular weight. This assumption seems to be highly irregular, as the polymer solubility should increase with temperature. 


\section{SUMMARY}

A study was made of the mechanism of interfacial polyamidation and polyesterification by means of chemical kinetics and the carbon-14 isotope effect. Piperaine in an aqueous basic solution and phthaloyl chloride in carbon tetrachloride solution was chosen as the system for the polyamidation study; and 4,4'-isopropylidene diphenol in an aqueous basic solution and phthaloyl chloride in carbon tetrachloride solution was chosen as the system for the polyesterification study. Both polyamidation and polyesterification were foumd to be second-order reactions, producing high molecular weight polymers at low extent reaction.

Carboxy carbon-14 labeled phthaloyl chloride was prepared from carbon-14 barium carbonate by a series of reactions. The labeled phthaloyl chloride was then reacted with piperazine and with 4, 4'-isopropylidene diphenol in order to test for the presence of an experimental isotope effect. No detectable isotope effect was found for either polyesterification or polyamidation. Carboxy carbon-14 labeled benzoyl chloride was prepared from carbon-14 benzoic acid. The labeled benzoyl chloride was reacted with morpholine, and an experimental isotope effect was: observed.

Additional information was obtained from diffusion studies, the determination of apparent activation energies for polyamidation and polyesterification, intrinsic viscosity determinations, and the effect of varying the ratio of one monomer to the other monomer.

From the experimental information gathered in this study, a 
mechanism is proposed for the reaction course of polyamidation and polyesterification. 


\section{BIBLIOGRAPHY}

(1) Beaman, R. G., P. W.Morgan, C. R. Koller, E. L. Wittbecker, and E. E. Magat, J. Polymer Sci., 40, 329 (1959).

(2) Bigeleisen, J., J. Chem. Phys., 17, 675 (1949).

(3) Bigeleisen, J., and M. Mayer, J. Chem. Phys., 15, 26 (1947)。

(4) Bigeleisen, J., and M. Wolfsberg, "Advances in Chemical Physics," Vo1, 1, Interscience Publishers Inc., New York, 1958, p. 38.

(5) Bohme, H. and W. Schurhoff, Ber, , 84, 28 (1951).

(6) Buist, G. J. and M. I. Bender, J. Am. Chem. Soc., 80, 4308-11 $(1958)$.

(7) Bunton, C. A., T. A. Lewis, and D. R. Llewellyn, Chem. and Ind., I3, $1154(1954)$.

(8) D'Alelio, G. F., "Fundamental Principles of Polymerization." John Wiley \& Sons, Inc., New York, 1952.

(9) Dixon, W. J. and F. J. Massey, "Introduction To Statistical Analysis." McGraw-Hil1 Book Co., New York, 1951, p. 156.

(10) Eareckson, W. M., J. Polymer Sci., 40, 399 (1959).

(11) Flory, P. J., Chem. Rev., 32, 137-97 (1946).

(12) Flory, P. J., I. Am. Chem. Soc., 29, 466 (1937).

(13) Flory, P. J., J. Am. Chem. Soc., 61, 3334 (1939).

(14) Flory, P. J., U. S. Patent 2,244,191. 1941.

(15) Hall, H. K., J. Am. Chem. Soc., 77, 5993 (1955).

(16) Hodgman, C., Ed., "Tables for Identification or Organic Compounds." Chemical Rubber Co., Cleveland, 1960.

(17) Jensen, A. W., Ph.D. Thesis, Oklahoma State University, Stillwater, Oklahoma, 1958.

(18) Katz, M.; E. I. du Pont de Nemours \& Co., wilmington, Delaware, private communication. 
(19) Katz, M., J. Polymer Sci., 40, 337 (1959).

(20) Kyrides, L. P., J. Am. Chem. Soc., 59, 206 (1937).

(21) Lange, N. A., Ed., "Handbook of Chemistry." Eighth Edition, Handbook Publishers Inc., Sandusky, Ohio, 1952.

(22) Lapp, R. E. and H. L. Andrews, "Nuclear Radiation Physics." Prentice-Ha11, Inc., New York, 1948, p. 336.

(23) Lyman, D. J. and S. L. Jung, J. Polymer Sci., 40, 407 (1959).

(24) Marvel, C. S. and McColm, Org. Syntheses, Col1. Vol. I, 536 (1941).

(25) Morgan, P. W. and S. L. Kwolek, J. Chem. Ed., 36, 182-4 (1959).

(26) Morgan, P. w. and S. L. Kwolek, J. Polymer Sci., 40, 299 (1959).

(27) Morgan, P. W. and 0. R. Strachan, U. S. Patent 2,708,617. 1955.

(28) Murray, A. and D. L. Williams, "Organic Syntheses With Radioisotopes."--Part I. Interscience Publishers, Inc., New York, 1957, p. 439.

(29) Ott, E., Ber., 70, 2360 (1937).

(30) Raaen, V. R. and G. A. Ropp, Anal. Chem., 25, 174 (1953).

(31) Reissert, A. and H. Ho1le, Ber., 44, 3029 (1911).

(32) Roginsky, S. 2., "Theoretical Principles of Isotope Methods for Investigating Chemical Reactions." Academy of Sciences U.S.S.R. Press, Moscow, 1956; A.E.C. Translation No. 2873.

(33) Ropp, G. A., Nucleonics, 10, No. 10, 22 (1952).

(34) Rowton, R. L., Ph.D. Thesis, Oklahoma State University, Stillwater, Ok1ahoma, 1959.

(35) Schaefgen, J. R., F. H. Koonz, and R. F. Tietz, J. Polymer Sci., 40, 377 (1959).

(36) Shashoua, V. E. and W. M. Eareckson, J. Polymer Sci., 40, 343 (1959).

(37) Stephens, C. w., J. Polymer Sci., 40, 359 (1959).

(38) Stevens, W. and R. Attree, an. J. Research, B27, 807 (1949).

(39) Sundet, S. A., W. A. Murphey, and S. B. Speck, J. Polymer Sci., 40, 389 (1959).

(40) Wilson, E. B., "An Introduction To Scientific Research." McGrawHill Book Co., New York, 1952, p. 239. 
(41) Wittbecker, E. L, and M. Katz, I. Polymer Sci., 40, 367 (1959).

(42) Wittbecker, E. L. and P. W. Morgan, I. Polymer Sci., 40, 289 (1959),

(43) Wittbecker, Morgan, Beaman, Koller, Magat, Sundet, Murphey, Speck, Schaefgen, Koonz, Tietz, and Eareckson; a series of papers presented before the Division of Polymer Chemistry at the 134th Meeting of the American Chemical Society, September, 1958. 


\author{
VITA \\ Donald Albert Holmer \\ Candidate for the Degree of \\ Doctor of Philosophy
}

Thesis: A STUDY OF THE MECHANISM OF INTERFACIAL POLYAMIDATION AND POLYESTER IF ICATION

Major Field: Organic Chemistry

Biographical:

Personal Data: Born March 29, 1934, Lead, South Dakota.

Undergraduate Study: Bachelor of Science Degree, South Dakota School of Mines and Technology, Rapid City, South Dakota, $1952-1956$.

Professional Experience: Analytical Chemist at Homestake Mining Company, Lead, South Dakota, Summers of 1954, 1955, 1956.

Research Assistant at Los Alamos Scientific Laboratory, Los

Alamos, New Mexico, Summer of 1957. Research Chemist at

E. I. duPont de Nemours Company, Waynesboro, Virginia, Summer of 1958. Teaching Assistant, Oklahoma State University, 19561957. A. E. C. Research Assistant, Oklahoma State University, 1957-1958. Texaco Fellow, Oklahoma State University, 19581960. 